Original Research Paper

\title{
Mycobacterium tuberculosis Complex Mutations in Drug Resistant Clinical Isolates from Southwest Mexico
}

\author{
${ }^{1,5}$ Martínez-Cruz Perla Mónica, ${ }^{2,6}$ Nakamura-López Yuko, ${ }^{3}$ Quintero-Hernández Verónica, \\ ${ }^{4}$ Pérez-Campos Mayoral Laura and ${ }^{5}$ Martínez-Martínez Lucía Lourdes \\ ${ }^{I}$ División de Estudios de Posgrado e Investigación, Instituto Tecnológico de Oaxaca, Oaxaca, Mexico \\ ${ }^{2}$ Unidad de Epidemiología. Dirección de Prevención y Promoción a la Salud. Servicios de Salud de Oaxaca. Oaxaca, Mexico \\ ${ }^{3}$ CONACYT-Laboratorio de Ecología Molecular Microbiana, Centro de Investigaciones en Ciencias Microbiológicas-Instituto \\ de Ciencias, Benemérita Universidad Autónoma de Puebla, Puebla, Mexico \\ ${ }^{4}$ Centro de Investigación Facultad de Medicina UNAM-UABJO, Facultad de Medicina y Cirugía, Universidad Autónoma \\ "Benito Juárez" de Oaxaca, Oaxaca, Mexico \\ ${ }^{5}$ Laboratorio de Biología Molecular, Centro de Investigación, Facultad de Medicina UNAM-UABJO, Universidad Autónoma \\ "Benito Juárez" de Oaxaca, Oaxaca, Mexico \\ ${ }^{6}$ Red Multidisciplinaria de Investigación en Tuberculosis (RemiTB; www.remitb.org). Red Nacional de Investigación para la \\ Prevención y Control de la Tuberculosis en México
}

Article history

Received: 02-06-2021

Revised: 10-08-2021

Accepted: 26-08-2021

Corresponding Author:

Martínez-Martínez Lucía

Lourdes

Laboratorio de Biología

Molecular, Centro de

Investigación, Facultad de

Medicina UNAM-UABJO,

Universidad Autónoma"Benito

Juárez" de Oaxaca, Oaxaca,

Mexico

Email: lumartin1969@yahoo.com.mx

\begin{abstract}
Mutations in target genes have been described in Mycobacterium tuberculosis Complex (MTBc) drug resistant isolates worldwide. In Mexico, not enough information has been reported in this concern. The aim of this study was to characterize mutations related to resistance to first line drugs in MTBc isolates from Oaxaca, Mexico. MTBc isolates were identified in clinical samples from Tuberculosis (TB) patients. Susceptibility to isoniazid, rifampin, ethambutol, streptomycin and pyrazinamide was tested through nitrate reductase assay. PCR based analysis and sequencing were employed to characterize mutations in $k a t \mathrm{G}, i n h \mathrm{~A}, r p o \mathrm{~B}, e m b \mathrm{~B}, r r s, r p s \mathrm{~L}$ and $p n c \mathrm{~A}$ genes. Mutations in kat $\mathrm{G}$ and the promoter of the mabA-inhA operon were found in isoniazid resistant isolates. Sequence analysis of Rifampin ResistanceDetermining Region in the $r p o \mathrm{~B}$ gene showed novel mutations along this region besides mutations at codons 516, 526 and 531. Polymorphisms at codon 306 $e m b \mathrm{~B}$ gene were found in ethambutol resistant isolates. Frequent mutations associated to resistance to streptomycin were characterized in $r r s$ and/or $r p s \mathrm{~L}$ genes. pncA analysis showed variable number of mutations in resistant and susceptible pyrazinamide isolates. Most frequent mutations related to resistance to first line antituberculous drugs were identified in phenotypically resistant $\mathrm{MTBc}$ isolates. New mutations were characterized in $r p o \mathrm{~B}, r r s$ and $r p s \mathrm{~L}$ genes.
\end{abstract}

Keywords: Tuberculosis, First-Line-Drugs, PCR, Sequencing

\section{Introduction}

According to World Health Organization (WHO) tuberculosis (TB) is one of the top ten causes of death and the leading cause from a single infectious agent, causing 1.2 million deaths around the world. Mexico ranks third in the Americas region, just below Brazil and Peru, with 23 cases per 100,000 persons (WHO, 2019). TB is caused by nine mycobacterial species clustered as Mycobacterium tuberculosis Complex (MTBc), namely: $M$. tuberculosis, $M$. bovis, $M$. africanum, $M$. microti, $M$. canettii, $M$. caprae, $M$. pinnipedii, M. mungi and M. orygis.

Once TB is diagnosed, first line antituberculous drugs are administered: isoniazid (INH), rifampin (RIF), ethambutol (EMB), streptomycin (STR) and pyrazinamide (PZA). Antimycobacterial drugs may inhibit cell wall synthesis (INH, EMB), interfere with DNA replication and protein synthesis (RIF, STR) or acidify cytoplasmic environment altering metabolic pathways (PZA) (Fig. 1) (Cuevas-Córdoba et al., 2013a; Malone et al., 2016). Increasing number of TB cases is partly due to the transmission of drug resistant strains.

Drug Resistance (DR) in MTBc strains has been explained by mutations occurring in the different genes that encode for target proteins for each first line antituberculous drug: $k a t \mathrm{G}$ and $\operatorname{inh} \mathrm{A}(\mathrm{INH}), \operatorname{rpoB}$ (RIF), embB (EMB), rrs and rpsL (STR) and pncA (PZA) (Abbadi et al., 2009; Bakuła et al., 2013; Cuevas-Córdoba et al., 2013b; Pang et al., 2017). 


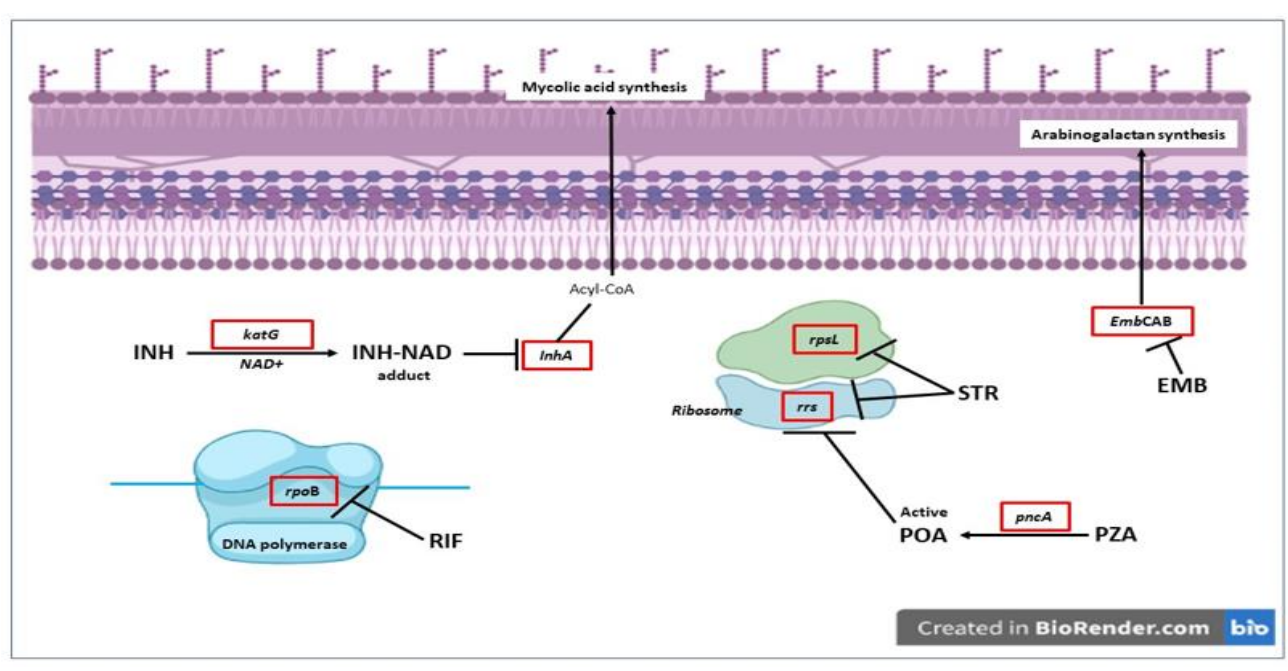

Fig. 1: Metabolic pathways disrupted by first line antimycobacterial drugs. Abbreviations: INH, isoniazid; RIF, rifampin; EMB, ethambutol; STR, streptomycin; PZA, pyrazinamide; POA, pirazinoic acid; NAD, nicotinamide adenine dinucleotide. Adapted from Malone et al. (2016)

Reports from different regions around the world have coincide in the occurrence of specific and recurring mutations in those genes. Thus, mutations at codon 315 in the $k a t \mathrm{G}$ gene or within the rifampin Resistance-Determining Region (RRDR) in the rpoB gene or in codon 306 of $e m b \mathrm{~B}$ gene have been used to identify resistant strains. In contrast, mutations in rrs, $r p s \mathrm{~L}$ and $p n c \mathrm{~A}$ genes related to DR vary between reports although there have been few coincidences.

In Mexico, molecular data about DR is scarce and restricted to the high TB incidence states of the country. In Oaxaca, located in the southwest of Mexico, TB incidence is above national rate and molecular drug resistance information has not been reported. Therefore, the aim of this study was to characterize mutations related to resistance to first line drugs in MTBc isolates from Oaxaca, Mexico.

\section{Materials and Methods}

\section{Sample Collection and Decontamination}

Two hundred fifty clinical samples from newly diagnosed TB patients were collected between September 2016 and September 2018 through ten different public health institutions throughout Oaxaca State. Some 199 (79\%) samples were pulmonary (sputum) and $51(21 \%)$ were extra-pulmonary (pleural liquid, cerebrospinal fluid, bronchial lavage, biopsy, gastric fluid, pericardial fluid, urine, peritoneal fluid, feces and blood). Pulmonary samples were decontaminated following Petroff's modified method as previously described (Peres et al., 2009). Decontaminated samples were used for DNA extraction and nitrate reductase assay.

\section{Ziehl-Neelsen Stain}

Clinical samples were smeared on slides and stained by the conventional Ziehl-Neelsen method for the presence of Acid Fast Bacilli (AFB). Slides were covered with $3 \%$ basic fuchsin, heated gently until it produced fumes and gently washed with flowing tap water. Slides were then decolorized with acid-alcohol solution (35\% chlorhydric acid/95\% ethanol) and counterstained with methylene blue dye. Finally, they were observed under a light microscope.

\section{Calculation of positive and negative Agreement}

The proportion of agreements between two tests (X and $\mathrm{Y}$ ) and standard error were calculated using the formulae described by Nagarajan et al., 2012:

$$
\text { Positive agreement }=\frac{2 a}{2 a+b+c}
$$

$$
\text { Negative agreement }=\frac{2 d}{2 d+b+c}
$$

Standard error for positive agreement $=\frac{\sqrt{[4 a(c+b)(a+c+b)]}}{(2 a+b+c)^{2}}$

Standard error for negative agreement $=\frac{\sqrt{[4 d(c+b)(d+c+b)]}}{(2 d+b+c)^{2}}$

Where:

$a$ - Number of samples positive by both $X$ and $Y$ tests

$b$ - Number of samples positive by $X$ test and negative by $\mathrm{Y}$ test

$c$ - Number of samples negative by $X$ test and positive by $Y$ test

$d$ - Number of samples negative by both $X$ and $\mathrm{Y}$ tests 


\begin{tabular}{|c|c|c|c|}
\hline Gene & Primer & Sequence (5'- 3') & Amplicon size \\
\hline \multirow[t]{2}{*}{$\overline{g y r \mathrm{~B}}$} & MTUBf & tcggacgcgtatgcgatatc & $1020 \mathrm{pb}$ \\
\hline & $\mathrm{MTUBr}$ & acatacagttcggacttgcg & \\
\hline \multirow[t]{2}{*}{$k a t G$} & KatgOF & gcagatggggctgatctacg & $296 \mathrm{pb}$ \\
\hline & R315mut & tccatacgacctcgatgccag & \\
\hline \multirow[t]{2}{*}{$\operatorname{inh} A$} & mabAF & cgaagtgtgctgagtcacaccg & $146 \mathrm{pb}$ \\
\hline & inhARmut & agtcacccegacaacctatta & \\
\hline \multirow[t]{5}{*}{ rpoB } & ARMS516 & cagctgagccaattcacgga & $261 \mathrm{pb}$ \\
\hline & ARMS526 & cgctgtcggggttgtccc & $230 \mathrm{pb}$ \\
\hline & ARMS531 & acccacaagcgccgacagtc & $216 \mathrm{pb}$ \\
\hline & CtrlFw & cgaatatctggtccgcttgc & \\
\hline & ComRv & gtcgaccaccttgcggtacg & $537 \mathrm{pb}$ \\
\hline \multirow[t]{4}{*}{$e m b \mathrm{~B}$} & Emb1F & gggcggggctcaattgcc & $324 \mathrm{pb}$ \\
\hline & Emb2R & gcgcatccacagactggcgtc & \\
\hline & Emb306A & gacgacggctacatcetgggca & $160 \mathrm{pb}$ \\
\hline & Emb306B & ggtcggcgactcgggec & $210 \mathrm{pb}$ \\
\hline \multirow[t]{2}{*}{$r r s$} & PR13F & aaacctctttcaccatcgac & $552 \mathrm{pb}$ \\
\hline & PR30R & caggtaaggttcttcgcgttg & \\
\hline \multirow[t]{2}{*}{$r p s \mathrm{~L}$} & STR52R & gtcaagaccgcggctctgaa & $272 \mathrm{pb}$ \\
\hline & STR43F & ttcttgacaccetgcgtatc & \\
\hline \multirow[t]{2}{*}{$p n c \mathrm{~A}$} & pncA-F & aacagttcatcccggttc & $668 \mathrm{pb}$ \\
\hline & pncA-R & gcgtcatggaccctatatc & \\
\hline
\end{tabular}

PCR was taken as standard test for comparison of the agreements between Ziehl-Neelsen stain and culture.

\section{Nitrate Reductase Assay}

The assay was conducted as previously described (Abilleira et al., 2014) using first line drugs concentrations as recommended $(0.2 \mu \mathrm{g} / \mathrm{mL}$ isoniazid, $1 \mu \mathrm{g} / \mathrm{mL}$ rifampicin, $100 \mu \mathrm{g} / \mathrm{mL}$ pyrazinamide, $2 \mu \mathrm{g} / \mathrm{mL}$ streptomycin and $7.5 \mu \mathrm{g} / \mathrm{mL}$ ethambutol) (OMS, 2012).

\section{Molecular Assays}

All PCR assays described below were conducted in $25 \mu \mathrm{L}$ volume reaction containing $1 X$ Buffer, $25 \mathrm{mM}$ $\mathrm{MgCl}_{2}, 10 \mathrm{mM}$ dNTPs mix, $1.25 \mathrm{U}$ taq polymerase (GoTaq Flexi DNA Polymerase, Promega. Madison, WI, USA), $1.0 \mu \mathrm{L}$ DNA and the corresponding primers.

\section{Mycobacterium tuberculosis Complex (MTBc) Identification}

Genomic DNA was extracted using the phenolchloroform method as described elsewhere (De Almeida et al., 2013) and quantified by UV spectrophotometry (Nanodrop Lite, Thermo Scientific. Waltham, MA, USA). DNA was observed by $0.8 \%$ agarose gel electrophoresis. MTBc isolates were identified by PCR amplification of a $1020 \mathrm{bp}$ fragment of the gyr $\mathrm{B}$ gene employing $50 \mu \mathrm{M}$ MTUBf and MTUBr primers (Table 1) (Abass et al., 2010; Chimara et al., 2004) and verified by $1 \%$ agarose gel electrophoresis. Mycobacterium species were identified using Huard's panel as previously described (Huard et al., 2003).

\section{Multiplex PCR}

Evaluation of mutations associated to isoniazid resistance in $k a t \mathrm{G}$ gene and promoter of the mabA-inh $\mathrm{A}$ operon was conducted via multiplex PCR assay as previously described (Herrera-León et al., 2005). PCR mix contained $200 \mu \mathrm{M}$ MTUBf, MTUBr, KatGOF and R315mut primers plus $400 \mu \mathrm{M}$ mabAF and InhARmut primers (Table 1). Products were analyzed on $1 \%$ agarose gel electrophoresis.

\section{Amplification Refractory Mutation System (ARMS)}

Mutations in codons 516, 526 and 531 in rpoB gene were assessed by ARMS (Fan et al., 2003). Three independent PCR reactions were conducted using $50 \mu \mathrm{M}$ CtrlFw, ComRv and ARMS516 or ARMS526 or ARMS531 primers (Table 1). PCR products were analyzed on $1.5 \%$ agarose gel electrophoresis. When mutations were detected in any of the studied codons, a $537 \mathrm{bp}$ fragment was amplified employing $50 \mu \mathrm{M} \mathrm{CtrlFw}$ and ComRv primers and sequenced for further analysis.

\section{Multiplex Allele-Specific PCR Assay (MAS-PCR)}

Mutations in the first and third nucleotides of codon $306 e m b \mathrm{~B}$ gene were assessed simultaneously by MAS-PCR (Mokrousov et al., 2002). $50 \mu \mathrm{M}$ Emb1F, Emb2R, Emb306A and Emb306B primers were included in the same PCR reaction (Table 1). PCR products were analyzed on $3 \%$ agarose gel electrophoresis. For those isolates in which mutations were detected, a $324 \mathrm{bp}$ fragment was amplified employing Emb1F and Emb2R primers which was sequenced for further analysis.

\section{rrs, rpsL and pncA Amplification}

PCR products for $r r s, r p s \mathrm{~L}$ and $p n c \mathrm{~A}$ genes were obtained using specific primers (Table 1) in independent PCR reaction mixes including $50 \mu \mathrm{M}$ PR13F/PR30R (rrs) or $50 \mu \mathrm{M}$ STR52R/STR43F (rpsL) (Cuevas-Córdoba et al., 
2013a) or $50 \mu \mathrm{M}$ pncA-F/pncA-R (pncA) (Pang et al., 2017 ) primers. PCR products were analyzed on $1.5 \%$ agarose gel electrophoresis.

\section{Sequencing and Mutation Characterization}

Amplification products for $r p o \mathrm{~B}, e m b \mathrm{~B}, r r s, r p s \mathrm{~L}$ and $p n c \mathrm{~A}$ genes were purified (Wizard SV Gel and PCR Clean-up System, Promega. Madison, WI, USA) and sequenced using Sanger sequencing performed at Macrogen Inc. (Seoul, South Korea). Sequences were analyzed and mutations characterized by the multiple sequence alignment program Clustal Omega (EMBL-EBI) (Madeira et al., 2019). GenBank sequences for $M$. tuberculosis H37Rv strain were used as reference for each gene: $r p o B$ (ID: 888164), $e m b \mathrm{~B}$ (ID: 886126), rrs (ID: 2700429), rpsL (ID: 888259) and pncA (ID: 888260).

\section{Results}

\section{Mycobacterium tuberculosis Isolates Drug Resistance Profile}

MTBc isolates were identified in $15.2 \%$ (38) of the 250 clinical samples by $g y r \mathrm{~B}$ gene $1020 \mathrm{bp}$ fragment amplification, all belonged to TB patients. Ziehl-Neelsen stain showed that $18 / 38$ isolates were acid-fast positive while 7/38 were acid-fast negative. The remaining 13 isolates were directly cultured. Mycobacterium species identification showed that in most isolates (37/38) $M$. tuberculosis was the infective species while $M$. bovis was present in one isolate (56-ex).

Proportion of agreement was used to compare Ziehl-Neelsen stain and culture with PCR as standard in the identification of MTBc in clinical isolates. The positive agreement of Ziehl-Neelsen stain with PCR was $0.64 \pm 0.042$ and that of culture with PCR was found to be $0.66 \pm 0.036$. The negative agreement of Ziehl-Neelsen stain with PCR results was $0.181 \pm 0.059$ and that of culture with PCR was $0.0 \pm 0.0$.

Drug Resistance (DR) profile as determined by nitrate reductase assay on the $38 \mathrm{MTBc}$ isolates showed 17 (44.7\%) were multidrug resistant (MDR), 15 of which were resistant to at least another drug besides INH and RIF. Five (13.1\%) isolates were monoresistant; $13(34.2 \%)$ polyresistant and 2 $(5.2 \%)$ were pansusceptible. No DR profile could be obtained for one isolate as growth was not registered in the control wells along the phenotypic assay (Table 2).

\section{Drug Resistance Related Mutations}

According to molecular data, mutations S315T kat $\mathrm{G}$ and $\mathrm{C}-15 \mathrm{~T}$ in the promoter of the $m a b A$-inhA operon are most frequently related to INH resistance. The presence of those mutations in the $38 \mathrm{MTBc}$ isolates was evaluated employing a PCR multiplex assay. Three isolates showed S315T katG mutation and three showed C-15T mabA-inhA mutation; five of those isolates were phenotypically resistant to INH. In 18 isolates, resistant to INH according to phenotypic analysis, no mutations were identified at the analyzed positions. All INH susceptible isolates showed neither mutation. Two isolates with mutation $\mathrm{S} 315 \mathrm{~T}$ kat $\mathrm{G}$ were resistant to all first line drugs and two isolates that showed mutation C-15T mabA-inhA were MDR (Table 2).

$r p o \mathrm{~B}$ gene analysis through ARMS revealed mutations at codons 516, 526 or 531 in eleven isolates. Nevertheless, sequence analysis showed mutations just in five of them: 526 $(\mathrm{CAC} \rightarrow \mathrm{TAC})$, one isolate; 531 (TCG $\rightarrow \mathrm{TTG})$, three isolates and $516(\mathrm{GAC} \rightarrow \mathrm{GAA}) / 526(\mathrm{CAG} \rightarrow \mathrm{CAA})$, one isolate. Nitrate reductase assay showed that the isolate containing mutations at codons 516/526 was susceptible to RIF, while the rest, were resistant to the drug. Those with mutations at codon 531 were MDR. Sequence analysis of the whole RRDR (81 bp, codons 507-533) contained in the amplified $537 \mathrm{bp} \mathrm{rpoB}$ fragment for the above mentioned five isolates, revealed several mutations along this region in two isolates, none of them reported on the TB Drug Resistance Mutation Data Base (Sandgren et al., 2009) (Table 3). Interestingly, isolates with mutations at codon 531 contained no additional mutations along the RRDR.

Most EMB resistant cases have been explained by mutations in $e m b \mathrm{~B}$ gene, specifically at the first and third nucleotides in codon 306. Multiplex PCR and sequence results revealed mutations in six isolates (6/38), three with ATG $\rightarrow$ GTG substitution and three with ATG $\rightarrow$ ATA polymorphism. Except for one, all isolates were phenotypically resistant to EMB and at least to another first line drug as well (Table 2).

Drug resistance to STR has been related with mutations at $r r s$ and $r p s \mathrm{~L}$ genes, which encode for $16 \mathrm{~S}$ rRNA and ribosomal protein S12, respectively. Sequence analysis of $552 \mathrm{pb}$ rrs fragment, revealed that 23 of the 38 isolates had mutations at nucleotides $485(\mathrm{~A} \rightarrow \mathrm{G})$ and/or $906(\mathrm{~A} \rightarrow \mathrm{C} / \mathrm{T})$ and/or $907(\mathrm{~A} \rightarrow \mathrm{T} / \mathrm{G}) ; 18$ of those isolates were phenotypically resistant to STR (Table 2). Concerning rpsL gene, mutations in codons 43 and 88 have been most frequently associated to resistance to STR. In the present study, mutations in those positions were identified in eleven isolates: 43 (AAG $\rightarrow$ ACG/AGG) and 88 (AAG $\rightarrow$ GTG/AGG/AGA/GAA). Ten of those isolates were phenotypically resistant to STR.

Interestingly, some previously unreported mutations in STR resistant isolates were characterized in $r r s$ and rps $\mathrm{L}$ genes, identifying one of those mutations, or a combination of them, in phenotypically STR resistant isolates (Table 4). It is worth mentioning that in 12 isolates, we found mutations in both genes (rrs-rpsL) simultaneously, 11 of them were resistant to STR according to phenotypic analysis (Table 2). Most frequent mutations identified in $r r s$ and $r p s \mathrm{~L}$ genes are summarized in Table 4. 
pncA sequence analysis revealed mutations in 7 of the 38 MTBc isolates. Only three of them possessed mutations at the so called hot spots (nucleotides 3-17, 61-85 and 132142), however, all were susceptible to PZA. Two isolates (2/7), phenotypically resistant to PZA, showed mutations along pncA gene, none of them at the hot spots (Table 2).

\section{Comorbidities, Mutations and Drug Resistance}

Among the 38 cases included in the study, most frequent comorbidities were Diabetes Mellitus (DM) (12), malnutrition (4) and HIV (4). Within DM patient isolates, $50 \%$ were phenotypically MDR and resistant at least to another drug, $16 \%$ were monoresistant and $34 \%$ were polyresistant. Among these isolates, genes related to STR resistance showed the highest polymorphism diversity, being the most frequent at nucleotides 485 and 795 in rrs and at codons 47 and 87 in $r p s \mathrm{~L}$, identified in 10 different isolates (Table 2). Mutations in $i n h \mathrm{~A}, k a t \mathrm{G}, r p o \mathrm{~B}$ and $e m b \mathrm{~B}$ were registered in one isolate each, resistant to INH, RIF and EMB, respectively. pncA mutations were found only in one isolate susceptible to PZA (Table 2).

In the malnutrition group, two isolates were MDR. In one of them, mutations at $r p o \mathrm{~B}$ and $e m b \mathrm{~B}$ genes were found, while both showed mutations in $r r s$ and/or $r p s \mathrm{~L}$ genes. In the last two isolates only mutations at rrs gene were characterized (Table 2).

Two isolates from TB-HIV coinfected patients were resistant to all first line drugs, but mutations in $k a t \mathrm{G}$, $e m b \mathrm{~B}, r r s$ and $r p s \mathrm{~L}$ genes were found only in one of them, while in the second, only mutations at rps L gene were identified. A third isolate showed mutations in $r r s$ related to STR resistance. Last isolate was pansusceptible, although mutations at pncA gene were found (Table 2).

Table 2: Molecular and phenotypic pattern of $38 \mathrm{MTBc}$ isolates.

\begin{tabular}{|c|c|c|c|c|c|c|c|c|c|c|c|c|c|}
\hline \multirow[b]{2}{*}{ Isolate } & \multirow[b]{2}{*}{ Comorbidity } & \multicolumn{5}{|c|}{ Drug resistance } & \multirow[b]{2}{*}{$k a t \mathrm{G}$} & \multirow[b]{2}{*}{$\operatorname{inh} \mathrm{A}$} & \multirow[b]{2}{*}{$r p o \mathrm{~B}$} & \multicolumn{3}{|l|}{ Analyzed genes } & \multirow[b]{2}{*}{$p n c \mathrm{~A}$} \\
\hline & & I & $\mathrm{R}$ & E & S & Z & & & & $e m b \mathrm{~B}$ & $r r s$ & $r p s \mathrm{~L}$ & \\
\hline 18-ex & $\mathrm{An} / \mathrm{Pn}$ & $\mathrm{R}$ & $\mathrm{S}$ & $\mathrm{R}$ & $\mathrm{R}$ & $\mathrm{R}$ & $\begin{array}{l}\text { No mutations } \\
\text { detected }\end{array}$ & $\begin{array}{l}\text { No mutations } \\
\text { detected }\end{array}$ & $\begin{array}{l}\text { No mutations } \\
\text { detected }\end{array}$ & $\begin{array}{l}\text { No mutations } \\
\text { detected }\end{array}$ & $\begin{array}{l}\text { No mutations } \\
\text { detected }\end{array}$ & 88 AAG-->GTG & $\begin{array}{l}\text { Nt } 315 \mathrm{G}-->\mathrm{C} \\
\text { Nt } 316 \mathrm{C}-->\mathrm{G} \\
\text { Nt } 323 \mathrm{G}-->\mathrm{C} \\
\text { Nt } 337 \mathrm{G}->\mathrm{A} \\
\text { Nt } 380 \mathrm{G}->\mathrm{C} \\
\text { Nt } 385 \mathrm{G}-->\mathrm{A} \\
\text { Nt } 523 \mathrm{G}-->\mathrm{A} \\
\text { Nt } 541 \mathrm{G}->\mathrm{C} \\
\text { Nt } 562 \mathrm{~T}-->\mathrm{C} \\
\text { Nt } 84 \text { deletion C } \\
\text { Nt } 305 \mathrm{~A}-->\mathrm{G} \\
\text { Nt } 306 \mathrm{G}->\mathrm{A} \\
\text { Nt } 307 \mathrm{C}->\mathrm{A} \\
\text { Nt } 309 \mathrm{~T}-->\mathrm{G} \\
\text { Nt } 310 \text { ins T } \\
\text { Nt } 311 \text { ins A } \\
\text { Nt } 312 \mathrm{~A}-->\mathrm{C} \\
\text { Nt } 313 \mathrm{C}-->\mathrm{A} \\
\text { Nt } 314 \mathrm{~A}-->\mathrm{G}\end{array}$ \\
\hline 19-ex & $\mathrm{DM} / \mathrm{Mn}$ & $\mathrm{S}$ & $\mathrm{S}$ & $\mathrm{R}$ & $\mathrm{R}$ & $\mathrm{S}$ & $\begin{array}{l}\text { No mutations } \\
\text { detected }\end{array}$ & $\begin{array}{l}\text { No mutations } \\
\text { detected }\end{array}$ & $\begin{array}{l}\text { No mutations } \\
\text { detected }\end{array}$ & 306 ATG --> ATA & $\begin{array}{l}\text { Nt } 485 \text { A-->G } \\
\text { Nt } 906 \text { A-->C }\end{array}$ & $\begin{array}{l}30 \text { CGT--> AGT } \\
31 \text { CGT-->CTT } \\
47 \text { TCG-->TGG } \\
87 \text { GTG-->TGA } \\
88 \text { AAG-->AGG } \\
89 \text { GAC-->ACC }\end{array}$ & $\mathrm{Nt} 85$ deleción C \\
\hline 20-ex & $\mathrm{N}$ & $\mathrm{R}$ & $\mathrm{R}$ & $\mathrm{R}$ & $\mathrm{R}$ & $\mathrm{R}$ & $\begin{array}{l}\text { No mutations } \\
\text { detected }\end{array}$ & $\begin{array}{l}\text { No mutations } \\
\text { detected }\end{array}$ & 531 TCG-->TTG & $\begin{array}{l}\text { No mutations } \\
\text { detected }\end{array}$ & $\begin{array}{l}\text { Nt } 485 \text { A-->G } \\
\text { Nt } 906 \text { A-->T } \\
\text { Nt } 907 \text { A-->T }\end{array}$ & $\begin{array}{l}30 \text { CGT--> AGT } \\
31 \text { CGT--> ATT } \\
47 \text { TCG-->TGG } \\
87 \text { GTG-->TGA } \\
\text { 88 AAG-->AGG }\end{array}$ & $\begin{array}{l}\text { No mutations } \\
\text { detected }\end{array}$ \\
\hline 23 -ex & $\mathrm{AH} / \mathrm{Pn}$ & $\mathrm{R}$ & $\mathrm{R}$ & $\mathrm{R}$ & $\mathrm{R}$ & $\mathrm{R}$ & $\begin{array}{l}\text { No mutations } \\
\text { detected }\end{array}$ & $\begin{array}{l}\text { No mutations } \\
\text { detected }\end{array}$ & $\begin{array}{l}\text { No mutations } \\
\text { detected }\end{array}$ & 306 ATG --> GTG & $\begin{array}{l}\text { Nt } 485 \mathrm{~A}->\mathrm{G} \\
\mathrm{Nt} 795 \mathrm{C}-->\mathrm{T}\end{array}$ & $\begin{array}{l}\text { No mutations } \\
\text { detected }\end{array}$ & $\begin{array}{l}\text { No mutations } \\
\text { detected }\end{array}$ \\
\hline 24-ex & HIV & $\mathrm{R}$ & $\mathrm{R}$ & $\mathrm{R}$ & $\mathrm{R}$ & $\mathrm{R}$ & $\begin{array}{l}\text { No mutations } \\
\text { detected }\end{array}$ & $\begin{array}{l}\text { No mutations } \\
\text { detected }\end{array}$ & $\begin{array}{l}\text { No mutations } \\
\text { detected }\end{array}$ & $\begin{array}{l}\text { No mutations } \\
\text { detected }\end{array}$ & $\begin{array}{l}\text { No mutations } \\
\text { detected }\end{array}$ & $\begin{array}{l}\text { 52 GTT-->TTT } \\
\text { 69 GGC-->GTC } \\
\text { 78 TCG-->TGG } \\
\text { 87 GTG-->TGA } \\
\text { 88 AAG-->AGG } \\
30 \text { GT-->AGT } \\
31 \text { CGT-->ATT } \\
40 \text { ACC-->ATC } \\
\text { 47 TCG-->TGG } \\
\text { 49 CTT-->ATT } \\
\text { 50 CGG-->GGG }\end{array}$ & $\begin{array}{l}\text { No mutations } \\
\text { detected }\end{array}$ \\
\hline 26-ex & $\mathrm{Mn}$ & $\mathrm{R}$ & $\mathrm{R}$ & $\mathrm{R}$ & $\mathrm{R}$ & $\mathrm{R}$ & $\begin{array}{l}\text { No mutations } \\
\text { detected }\end{array}$ & $\begin{array}{l}\text { No mutations } \\
\text { detected }\end{array}$ & 531TCG-->TTG & 306 ATG -->ATA & $\begin{array}{l}\text { No mutations } \\
\text { detected } \\
\text { Nt } 907 \text { A-->G }\end{array}$ & $\begin{array}{l}43 \text { AAG-->AGG } \\
30 \text { CGT-->AGT } \\
47 \text { TCG-->TGG } \\
69 \text { GGC-->GTC } \\
87 \text { GTG-->TGA } \\
88 \text { AAG-->AGG } \\
78 \text { TCG--> TGG } \\
81 \text { CTG-->GAG } \\
84 \text { GGC-->GTC } \\
87 \text { GTC-->GTA }\end{array}$ & $\begin{array}{l}\text { No mutations } \\
\text { detected } \\
\text { Nt } 266 \mathrm{C}-->\mathrm{A} \\
\text { Nt } 280 \mathrm{~T}-->\mathrm{G} \\
\text { Nt } 296 \mathrm{C}-->\mathrm{T} \\
\text { Nt } 323 \mathrm{G}-->\mathrm{A} \\
\text { Nt } 335 \mathrm{G}-->\mathrm{A} \\
\text { Nt } 337 \mathrm{G}-->\mathrm{A} \\
\text { Nt } 340 \mathrm{C}-->\mathrm{A} \\
\text { Nt } 343 \mathrm{C}-->\mathrm{A}\end{array}$ \\
\hline
\end{tabular}


Martínez-Cruz Perla Mónica et al. / American Journal of Infectious Diseases 2021, 17 (4): 138.149 DOI: 10.3844/ajidsp.2021.138.149

\begin{tabular}{|c|c|c|c|c|c|c|c|c|c|c|c|c|}
\hline & & & & & & & & & & & 88 AAG->AGG & $\begin{array}{l}\text { Nt } 357 \text { A-->T } \\
\text { Nt } 365 \text { C-->G }\end{array}$ \\
\hline 27-ex & $\mathrm{N}$ & $\mathrm{R} \mathrm{S}$ & $S$ & $\mathrm{R}$ & $\mathrm{S}$ & $\begin{array}{l}\text { No mutations } \\
\text { detected }\end{array}$ & $\begin{array}{l}\text { No mutations } \\
\text { detected }\end{array}$ & $\begin{array}{l}\text { No mutations } \\
\text { detected }\end{array}$ & 306 ATG --> GTG & $\begin{array}{l}\text { Nt } 491 \mathrm{C}-->\mathrm{T} \\
\mathrm{Nt} 496 \mathrm{G}->\mathrm{C} \\
\mathrm{Nt} 516 \mathrm{C}-->\mathrm{T} \\
\mathrm{Nt} 907 \mathrm{~A} \rightarrow \mathrm{G}\end{array}$ & $\begin{array}{l}30 \text { CGT-->AGT } \\
31 \text { CGT-->ATT } \\
47 \text { TCG-->TGG } \\
49 \text { CTT-->ATT } \\
\text { 50 CGG-->GAG } \\
52 \text { GTT-->TTT } \\
57 \text { TTG-->CCG } \\
58 \text { ACG }-->\text { TCG } \\
60 \text { CAG-->CAA } \\
69 \text { GGC } \rightarrow \text { GTC } \\
70 \text { GAG-->GTG } \\
74 \text { CTG-->CGG } \\
78 \text { TCG } \rightarrow \text { TGG } \\
81 \text { CTG } \rightarrow \text { GAG } \\
84 \text { GGC } \rightarrow \text { GTC } \\
87 \text { GTC } \rightarrow \text { GTA } \\
88 \text { AAG } \rightarrow \text { AGG }\end{array}$ & 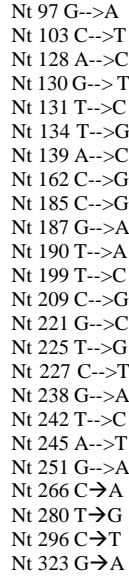 \\
\hline
\end{tabular}

\begin{tabular}{|c|c|c|c|c|c|c|c|c|c|c|c|c|c|}
\hline \multirow[b]{2}{*}{ Isolate } & \multirow[b]{2}{*}{ Comorbidity } & \multirow[b]{2}{*}{ I } & \multicolumn{4}{|c|}{ Drug resistance } & \multirow[b]{2}{*}{$k a t \mathrm{G}$} & \multirow[b]{2}{*}{$\operatorname{inh} \mathrm{A}$} & \multirow[b]{2}{*}{ rpoB } & \multicolumn{3}{|l|}{ Analyzed genes } & \multirow[b]{2}{*}{$p n c \mathrm{~A}$} \\
\hline & & & $\mathrm{R}$ & $\mathrm{E}$ & $\mathrm{S}$ & $\mathrm{Z}$ & & & & $e m b \mathrm{~B}$ & $r r s$ & $r p s \mathrm{~L}$ & \\
\hline$\overline{28-e x}$ & DM & $\mathrm{R}$ & $\mathrm{R}$ & $\mathrm{R}$ & $\mathrm{R}$ & $\mathrm{R}$ & $\begin{array}{l}\text { No mutations } \\
\text { detected }\end{array}$ & $\begin{array}{l}\text { No mutations } \\
\text { detected }\end{array}$ & $\begin{array}{l}\text { No mutations } \\
\text { detected }\end{array}$ & $\begin{array}{l}\text { No mutations } \\
\text { detected }\end{array}$ & $\begin{array}{l}\text { No mutations } \\
\text { detected }\end{array}$ & 47 TCG-->TGG & $\begin{array}{l}\text { No mutations } \\
\text { detected }\end{array}$ \\
\hline 30-ex & $\begin{array}{c}\mathrm{DM} / \mathrm{Mn} / \\
\mathrm{Ch} / \mathrm{Ht} / \mathrm{Pht}\end{array}$ & $\mathrm{R}$ & S & $\mathrm{S}$ & S & S & $\begin{array}{l}\text { No mutations } \\
\text { detected }\end{array}$ & $\begin{array}{l}\text { No mutations } \\
\text { detected }\end{array}$ & $\begin{array}{l}\text { No mutations } \\
\text { detected }\end{array}$ & $\begin{array}{l}\text { No mutations } \\
\text { detected }\end{array}$ & $\begin{array}{l}\text { Nt } 485 \mathrm{~A}-->\mathrm{G} \\
\mathrm{Nt} 795 \mathrm{C}->\mathrm{T} \\
\mathrm{Nt} 870 \mathrm{C}-->\mathrm{A} \\
\mathrm{Nt} 906 \mathrm{~A}->\mathrm{T}\end{array}$ & $\begin{array}{l}47 \text { TCG-->TGG } \\
87 \text { GTG-->TTG }\end{array}$ & $\begin{array}{l}\text { No mutations } \\
\text { detected }\end{array}$ \\
\hline 31-ex & $\mathrm{DM} / \mathrm{Sm}$ & $\mathrm{R}$ & $\mathrm{R}$ & $\mathrm{R}$ & $\mathrm{R}$ & $\mathrm{R}$ & $\begin{array}{l}\text { No mutations } \\
\text { detected }\end{array}$ & $\begin{array}{l}\text { No mutations } \\
\text { detected }\end{array}$ & $\begin{array}{l}\text { No mutations } \\
\text { detected }\end{array}$ & $\begin{array}{l}\text { No mutations } \\
\text { detected }\end{array}$ & $\begin{array}{l}\text { Nt } 485 \mathrm{~A}-->\mathrm{G} \\
\text { Nt } 795 \mathrm{C}-->\mathrm{T} \\
\text { Nt } 870 \mathrm{C}-->\mathrm{A} \\
\text { Nt } 906 \mathrm{~A}-->\mathrm{T} \\
\text { Nt } 907 \mathrm{~A}-->\mathrm{G}\end{array}$ & $\begin{array}{l}30 \text { CGT-->AGT } \\
31 \text { CGT-->ATT } \\
47 \text { TCG-->TGG } \\
87 \text { GTG-->TGC }\end{array}$ & $\begin{array}{l}\text { No mutations } \\
\text { detected }\end{array}$ \\
\hline 33 -ex & $\mathrm{N}$ & $\mathrm{R}$ & S & $\mathrm{S}$ & S & S & $\begin{array}{l}\text { No mutations } \\
\text { detected }\end{array}$ & $\begin{array}{l}\text { No mutations } \\
\text { detected }\end{array}$ & $\begin{array}{l}516 \text { GAC-->GAA } \\
526 \text { CAC-->CAA }\end{array}$ & $\begin{array}{l}\text { No mutations } \\
\text { detected }\end{array}$ & $\begin{array}{l}\text { Nt } 795 \mathrm{C}->>\mathrm{T} \\
\mathrm{Nt} 870 \mathrm{C}->\mathrm{A} \\
\mathrm{Nt} 906 \mathrm{~A}-->\mathrm{T} \\
\text { Nt } 907 \mathrm{~A}-->\mathrm{G}\end{array}$ & $\begin{array}{l}\text { No mutations } \\
\text { detected }\end{array}$ & $\begin{array}{l}\text { No mutations } \\
\text { detected }\end{array}$ \\
\hline 36-ex & DM & $\mathrm{R}$ & $\mathrm{R}$ & $\mathrm{R}$ & S & $\mathrm{R}$ & $\begin{array}{l}\text { No mutations } \\
\text { detected }\end{array}$ & $\begin{array}{l}\text { No mutations } \\
\text { detected }\end{array}$ & $\begin{array}{l}\text { No mutations } \\
\text { detected }\end{array}$ & $\begin{array}{l}\text { No mutations } \\
\text { detected }\end{array}$ & $\begin{array}{l}\text { No mutations } \\
\text { detected }\end{array}$ & $\begin{array}{l}\text { No mutations } \\
\text { detected }\end{array}$ & $\begin{array}{l}\text { No mutations } \\
\text { detected }\end{array}$ \\
\hline $37-e x$ & $\mathrm{HIV} / \mathrm{Mn} / \mathrm{Sm}$ & S & S & S & S & S & $\begin{array}{l}\text { No mutations } \\
\text { detected }\end{array}$ & $\begin{array}{l}\text { No mutations } \\
\text { detected }\end{array}$ & $\begin{array}{l}\text { No mutations } \\
\text { detected }\end{array}$ & $\begin{array}{l}\text { No mutations } \\
\text { detected }\end{array}$ & $\begin{array}{l}\text { No mutations } \\
\text { detected }\end{array}$ & $\begin{array}{l}\text { No mutations } \\
\text { detected }\end{array}$ & $\begin{array}{l}\text { Nt } 26 \text { G-->A } \\
\text { Nt } 27 \mathrm{G}-->\mathrm{A} \\
\mathrm{Nt} 174 \mathrm{C}-->\mathrm{T} \\
\mathrm{Nt} 218 \mathrm{~T}->\mathrm{G} \\
\mathrm{Nt} 262 \mathrm{~T}-->\mathrm{G} \\
\mathrm{Nt} 407 \mathrm{~A}-->\mathrm{T} \\
\mathrm{Nt} 440 \mathrm{G}-->\mathrm{C} \\
\mathrm{Nt} 474 \mathrm{~T}-->\mathrm{G} \\
\mathrm{Nt} 482 \mathrm{~A}->\mathrm{G} \\
\mathrm{Nt} 539 \mathrm{G}-->\mathrm{C}\end{array}$ \\
\hline $40-\mathrm{lb}$ & $\mathrm{Og} / \mathrm{Ep}$ & S & S & S & $\mathrm{R}$ & $\mathrm{R}$ & $\begin{array}{l}\text { No mutations } \\
\text { detected }\end{array}$ & $\begin{array}{l}\text { No mutations } \\
\text { detected }\end{array}$ & $\begin{array}{l}\text { No mutations } \\
\text { detected }\end{array}$ & $\begin{array}{l}\text { No mutations } \\
\text { detected }\end{array}$ & $\begin{array}{l}\text { Nt } 845 \mathrm{C}-->\mathrm{T} \\
\mathrm{Nt} 862 \mathrm{~A}->>\mathrm{G} \\
\mathrm{Nt} 867 \mathrm{G}-->\mathrm{A} \\
\mathrm{Nt} 877 \mathrm{~T}-->\mathrm{C} \\
\mathrm{Nt} 886 \mathrm{C}-->\mathrm{T} \\
\mathrm{Nt} 887 \mathrm{G}->\mathrm{A} \\
\mathrm{Nt} 926 \mathrm{G}-->\mathrm{C} \\
\mathrm{Nt} 928 \mathrm{~A}-->\mathrm{C} \\
\mathrm{Nt} 930 \mathrm{~A}-->\mathrm{C} \\
\mathrm{Nt} 932 \mathrm{G}->\mathrm{A} \\
\mathrm{Nt} 936 \mathrm{C}-->\mathrm{G} \\
\mathrm{Nt} 938 \mathrm{G}-->\mathrm{C}\end{array}$ & $\begin{array}{l}\text { No mutations } \\
\text { detected }\end{array}$ & $\begin{array}{l}\text { No mutations } \\
\text { detected }\end{array}$ \\
\hline 42-ex & DM & $\mathrm{R}$ & $\mathrm{R}$ & $\mathrm{R}$ & $\mathrm{R}$ & $\mathrm{R}$ & $315 \mathrm{~S} \rightarrow \mathrm{T}$ & $\begin{array}{l}\text { No mutations } \\
\text { detected }\end{array}$ & 526 CAC-->TAC & 306 ATG --> ATA & $\begin{array}{l}\text { Nt } 485 \mathrm{~A}->\mathrm{G} \\
\mathrm{Nt} 496 \mathrm{G}-->\mathrm{C} \\
\mathrm{Nt} 906 \mathrm{~A}-->\mathrm{C} \\
\mathrm{Nt} 907 \mathrm{~A}->\mathrm{T}\end{array}$ & 43 AAG -->AGG & $\begin{array}{l}\text { No mutations } \\
\text { detected }\end{array}$ \\
\hline
\end{tabular}


Martínez-Cruz Perla Mónica et al. / American Journal of Infectious Diseases 2021, 17 (4): 138.149 DOI: 10.3844/ajidsp.2021.138.149

\begin{tabular}{|c|c|c|c|c|c|c|c|c|c|c|c|c|c|}
\hline 43 -ex & $\mathrm{HIV/CSm}$ & $\mathrm{R}$ & $\mathrm{R}$ & $\mathrm{R}$ & $\mathrm{R}$ & $\mathrm{R}$ & $315 \mathrm{~S} \rightarrow \mathrm{T}$ & $\begin{array}{l}\text { No mutations } \\
\text { detected }\end{array}$ & $\begin{array}{l}\text { No mutations } \\
\text { detected }\end{array}$ & 306 ATG --> GTG & $\begin{array}{l}\text { Nt } 485 \text { A-->G } \\
\text { Nt } 514 \text { A-->C } \\
\text { Nt } 795 \text { C-->A } \\
\text { Nt } 906 \text { A-->T } \\
\text { Nt } 907 \text { A-->G }\end{array}$ & $\begin{array}{l}82 \text { GTG-->GTT } \\
84 \text { GGC-->TGC } \\
86 \text { CGG-->CTG }\end{array}$ & $\begin{array}{l}\text { No mutations } \\
\text { detected }\end{array}$ \\
\hline 45-ex & $\mathrm{DM} / \mathrm{Ow} / \mathrm{AH}$ & $S$ & S & $\mathrm{R}$ & $\mathrm{R}$ & S & $\begin{array}{l}\text { No mutations } \\
\text { detected }\end{array}$ & $\begin{array}{l}\text { No mutations } \\
\text { detected }\end{array}$ & $\begin{array}{l}\text { No mutations } \\
\text { detected }\end{array}$ & $\begin{array}{l}\text { No mutations } \\
\text { detected }\end{array}$ & $\begin{array}{l}\text { Nt } 485 \text { G-->A } \\
\text { Nt } 491 \text { G-->A } \\
\text { Nt } 492 \text { C-->T } \\
\text { Nt } 493 \text { A-->C } \\
\text { Nt } 494 \text { C-->G } \\
\text { Nt } 495 \text { C-->T }\end{array}$ & $\begin{array}{l}\text { No mutations } \\
\text { detected }\end{array}$ & $\begin{array}{l}\text { No mutations } \\
\text { detected }\end{array}$ \\
\hline 46-ex & $\mathrm{AH} / \mathrm{Al}$ & $\mathrm{S}$ & S & $\mathrm{S}$ & $\mathrm{S}$ & S & $\begin{array}{l}\text { No mutations } \\
\text { detected }\end{array}$ & $\begin{array}{l}\text { No mutations } \\
\text { detected }\end{array}$ & $\begin{array}{l}\text { No mutations } \\
\text { detected }\end{array}$ & $\begin{array}{l}\text { No mutations } \\
\text { detected }\end{array}$ & $\begin{array}{l}\text { Nt } 485 \mathrm{~A}-->\mathrm{G} \\
\text { Nt } 795 \mathrm{C}-->\mathrm{T} \\
\text { Nt } 906 \mathrm{~A}-->\mathrm{T}\end{array}$ & $\begin{array}{l}\text { No mutations } \\
\text { detected }\end{array}$ & $\begin{array}{l}\text { No mutations } \\
\text { detected }\end{array}$ \\
\hline 47-ex & $\mathrm{Dm} / \mathrm{AH} / \mathrm{Sm}$ & $\mathrm{S}$ & $\mathrm{R}$ & $\mathrm{R}$ & $\mathrm{R}$ & $\mathrm{R}$ & $\begin{array}{l}\text { No mutations } \\
\text { detected }\end{array}$ & $\begin{array}{l}\text { No mutations } \\
\text { detected }\end{array}$ & $\begin{array}{l}\text { No mutations } \\
\text { detected }\end{array}$ & $\begin{array}{l}\text { No mutations } \\
\text { detected }\end{array}$ & $\begin{array}{l}\text { Nt } 485 \text { A-->G } \\
\text { Nt } 496 \text { G-->C }\end{array}$ & $\begin{array}{l}\text { No mutations } \\
\text { detected }\end{array}$ & $\begin{array}{l}\text { No mutations } \\
\text { detected }\end{array}$ \\
\hline 48-ex & $\mathrm{N}$ & $\mathrm{S}$ & $\mathrm{R}$ & $S$ & $\mathrm{R}$ & $S$ & $\begin{array}{l}\text { No mutations } \\
\text { detected }\end{array}$ & $\begin{array}{l}\text { No mutations } \\
\text { detected }\end{array}$ & $\begin{array}{l}\text { No mutations } \\
\text { detected }\end{array}$ & $\begin{array}{l}\text { No mutations } \\
\text { detected }\end{array}$ & $\begin{array}{l}\text { Nt } 485 \mathrm{~A}->\mathrm{G} \\
\text { Nt } 906 \mathrm{A-->T}\end{array}$ & $\begin{array}{l}\text { No mutations } \\
\text { detected }\end{array}$ & Nt 39 Ins C \\
\hline
\end{tabular}

Table 2: Molecular and phenotypic pattern of $38 \mathrm{MTBc}$ isolates (cont.)

\begin{tabular}{|c|c|c|c|c|c|c|c|c|c|c|c|c|c|}
\hline \multirow[b]{2}{*}{ Isolate } & \multirow[b]{2}{*}{ Comorbidity } & \multicolumn{5}{|c|}{ Drug resistance } & \multirow[b]{2}{*}{ kat $\mathrm{G}$} & \multirow[b]{2}{*}{$\operatorname{inh} \mathrm{A}$} & \multirow[b]{2}{*}{$r p o \mathrm{~B}$} & \multicolumn{3}{|l|}{ Analyzed genes } & \multirow[b]{2}{*}{ pncA } \\
\hline & & I & $\mathrm{R}$ & $\mathrm{E}$ & $\mathrm{S}$ & Z & & & & $e m b \mathrm{~B}$ & $r r s$ & $r p s \mathrm{~L}$ & \\
\hline $\begin{array}{l}49-e x \\
\end{array}$ & $\mathrm{~N}$ & $\mathrm{~S}$ & $\mathrm{R}$ & $\mathrm{R}$ & $\mathrm{R}$ & $\mathrm{S}$ & $\begin{array}{l}\text { No mutations } \\
\text { detected }\end{array}$ & $\begin{array}{l}\text { No mutations } \\
\text { detected }\end{array}$ & $\begin{array}{l}\text { No mutations } \\
\text { detected }\end{array}$ & $\begin{array}{l}\text { No mutations } \\
\text { detected }\end{array}$ & $\begin{array}{l}\mathrm{Nt} 493 \mathrm{~A}-->\mathrm{G} \\
\mathrm{Nt} 494 \mathrm{C}-->\mathrm{T} \\
\mathrm{Nt} 495 \mathrm{C}-->\mathrm{G} \\
\mathrm{Nt} 496 \mathrm{~A}-->\mathrm{G} \\
\mathrm{Nt} 499 \mathrm{C}-->\mathrm{A}\end{array}$ & $\begin{array}{l}\text { No mutations } \\
\text { detected }\end{array}$ & $\begin{array}{l}\text { No mutations } \\
\text { detected }\end{array}$ \\
\hline 50-ex & $\mathrm{N}$ & $\mathrm{R}$ & S & $S$ & $\mathrm{R}$ & $\mathrm{R}$ & $\begin{array}{l}\text { No mutations } \\
\text { detected }\end{array}$ & $\begin{array}{l}\text { No mutations } \\
\text { detected }\end{array}$ & $\begin{array}{l}\text { No mutations } \\
\text { detected }\end{array}$ & $\begin{array}{l}\text { No mutations } \\
\text { detected }\end{array}$ & $\begin{array}{l}\text { Nt } 485 \mathrm{~A}->\mathrm{G} \\
\text { Nt } 795 \mathrm{C}->\mathrm{T} \\
\text { Nt } 906 \mathrm{~A}->>\mathrm{T} \\
\text { Nt } 907 \mathrm{~A}-->\mathrm{G}\end{array}$ & $\begin{array}{l}\text { No mutations } \\
\text { detected }\end{array}$ & $\begin{array}{l}\text { No mutations } \\
\text { detected }\end{array}$ \\
\hline $51-\mathrm{ex}$ & $\mathrm{Mn} / \mathrm{Sm}$ & $\mathrm{R}$ & $\mathrm{R}$ & $\mathrm{R}$ & $\mathrm{R}$ & $\mathrm{R}$ & $\begin{array}{l}\text { No mutations } \\
\text { detected }\end{array}$ & $\begin{array}{l}\text { No mutations } \\
\text { detected }\end{array}$ & $\begin{array}{l}\text { No mutations } \\
\text { detected }\end{array}$ & $\begin{array}{l}\text { No mutations } \\
\text { detected }\end{array}$ & $\begin{array}{l}\text { Nt } 795 \mathrm{C}-->\mathrm{T} \\
\text { Nt } 870 \mathrm{C}-->\mathrm{A} \\
\text { Nt } 906 \mathrm{~A}-->\mathrm{T} \\
\text { Nt } 907 \mathrm{~A}-->\mathrm{G}\end{array}$ & $\begin{array}{l}\text { 81 CTG-->CAA } \\
82 \text { GTG-->GAC } \\
\text { 84 GGC-->GGG } \\
85 \text { GGC-->CGT } \\
86 \text { CGG-->GCT } \\
\text { 88 AAG-->AGA } \\
\text { 89 GAC-->GCC }\end{array}$ & $\begin{array}{l}\text { No mutations } \\
\text { detected }\end{array}$ \\
\hline 53-ex & $\mathrm{N}$ & $\mathrm{R}$ & $\mathrm{R}$ & $\mathrm{R}$ & $\mathrm{R}$ & $\mathrm{R}$ & $\begin{array}{l}\text { No mutations } \\
\text { detected }\end{array}$ & $\begin{array}{l}\text { No mutations } \\
\text { detected }\end{array}$ & $\begin{array}{l}\text { No mutations } \\
\text { detected }\end{array}$ & $\begin{array}{l}\text { No mutations } \\
\text { detected }\end{array}$ & $\begin{array}{l}\text { Nt } 485 \mathrm{~A}-->\mathrm{G} \\
\text { Nt } 514 \mathrm{~A}-->\mathrm{C}\end{array}$ & 43 AAG-->ACG & $\begin{array}{l}\text { No mutations } \\
\text { detected }\end{array}$ \\
\hline 54-ex & $\mathrm{N}$ & $\mathrm{S}$ & $\mathrm{S}$ & $\mathrm{S}$ & $\mathrm{S}$ & $\mathrm{R}$ & $\begin{array}{l}\text { No mutations } \\
\text { detected }\end{array}$ & $\begin{array}{l}\text { No mutations } \\
\text { detected }\end{array}$ & $\begin{array}{l}\text { No mutations } \\
\text { detected }\end{array}$ & $\begin{array}{l}\text { No mutations } \\
\text { detected }\end{array}$ & Nt $491 \mathrm{C}-->\mathrm{A}$ & $\begin{array}{l}\text { No mutations } \\
\text { detected }\end{array}$ & $\begin{array}{l}\text { No mutations } \\
\text { detected }\end{array}$ \\
\hline 55 -ex & DM & S & $S$ & S & $\mathrm{R}$ & $\mathrm{S}$ & $\begin{array}{l}\text { No mutations } \\
\text { detected }\end{array}$ & $\begin{array}{l}\text { No mutations } \\
\text { detected }\end{array}$ & $\begin{array}{l}\text { No mutations } \\
\text { detected }\end{array}$ & $\begin{array}{l}\text { No mutations } \\
\text { detected }\end{array}$ & Nt 795 C-->T & $\begin{array}{l}\text { No mutations } \\
\text { detected }\end{array}$ & $\begin{array}{l}\text { No mutations } \\
\text { detected }\end{array}$ \\
\hline 56-ex & DM & $\mathrm{R}$ & $\mathrm{R}$ & $\mathrm{R}$ & $\mathrm{R}$ & $\mathrm{R}$ & $\begin{array}{l}\text { No mutations } \\
\text { detected }\end{array}$ & $\begin{array}{l}\text { No mutations } \\
\text { detected }\end{array}$ & $\begin{array}{l}\text { No mutations } \\
\text { detected }\end{array}$ & $\begin{array}{l}\text { No mutations } \\
\text { detected }\end{array}$ & Nt 485 A-->G & $\begin{array}{l}\text { No mutations } \\
\text { detected }\end{array}$ & $57 \mathrm{CAC} \rightarrow \mathrm{GAC}$ \\
\hline 60-bi & $\begin{array}{c}\mathrm{HIV} / \\
\mathrm{Sm} / \mathrm{Al} / \mathrm{CSm}\end{array}$ & $\mathrm{S}$ & $\mathrm{S}$ & $\mathrm{S}$ & $\mathrm{R}$ & $\mathrm{R}$ & $\begin{array}{l}\text { No mutations } \\
\text { detected }\end{array}$ & $\begin{array}{l}\text { No mutations } \\
\text { detected }\end{array}$ & $\begin{array}{l}\text { No mutations } \\
\text { detected }\end{array}$ & $\begin{array}{l}\text { No mutations } \\
\text { detected }\end{array}$ & Nt 795 C-->T & $\begin{array}{l}\text { No mutations } \\
\text { detected }\end{array}$ & $\begin{array}{l}\text { No mutations } \\
\text { detected }\end{array}$ \\
\hline 62-ex & $\begin{array}{c}\mathrm{Mn} \\
/ \mathrm{Sm} / \mathrm{As}\end{array}$ & $\mathrm{S}$ & $\mathrm{S}$ & $\mathrm{S}$ & $\mathrm{R}$ & $\mathrm{R}$ & $\begin{array}{l}\text { No mutations } \\
\text { detected }\end{array}$ & $\begin{array}{l}\text { No mutations } \\
\text { detected }\end{array}$ & $\begin{array}{l}\text { No mutations } \\
\text { detected }\end{array}$ & $\begin{array}{l}\text { No mutations } \\
\text { detected }\end{array}$ & $\begin{array}{l}\text { Nt } 485 \text { A-->G } \\
\text { Nt } 795 \text { C-->T }\end{array}$ & $\begin{array}{l}\text { No mutations } \\
\text { detected }\end{array}$ & $\begin{array}{l}\text { No mutations } \\
\text { detected }\end{array}$ \\
\hline 65 -ex & $\mathrm{N}$ & $\mathrm{Uk}$ & Uk & Uk & Uk & Uk & $315 \mathrm{~S} \rightarrow \mathrm{T}$ & $\begin{array}{l}\text { No mutations } \\
\text { Detected }\end{array}$ & 531 TCG-->TTG & $\begin{array}{l}\text { No mutations } \\
\text { detected }\end{array}$ & $\begin{array}{l}\text { Nt } 485 \mathrm{~A}-->\mathrm{G} \\
\mathrm{Nt} 906 \mathrm{~A}-->\mathrm{T} \\
\mathrm{Nt} 907 \mathrm{~A}-->\mathrm{T}\end{array}$ & $\begin{array}{l}\text { No mutations } \\
\text { detected }\end{array}$ & $\begin{array}{l}\text { No mutations } \\
\text { detected }\end{array}$ \\
\hline 68-ex & $\mathrm{DM} / \mathrm{Mn}$ & $\mathrm{R}$ & $\mathrm{R}$ & $\mathrm{R}$ & $\mathrm{R}$ & $\mathrm{R}$ & $\begin{array}{l}\text { No mutations } \\
\text { detected }\end{array}$ & $\begin{array}{l}\text { No mutations } \\
\text { detected }\end{array}$ & $\begin{array}{l}\text { No mutations } \\
\text { detected }\end{array}$ & $\begin{array}{l}\text { No mutations } \\
\text { detected }\end{array}$ & Nt 485 A-->G & $\begin{array}{l}\text { No mutations } \\
\text { detected }\end{array}$ & $\begin{array}{l}\text { No mutations } \\
\text { detected }\end{array}$ \\
\hline 186-ex & Uk & $\mathrm{R}$ & $\mathrm{R}$ & $\mathrm{R}$ & $\mathrm{R}$ & $\mathrm{S}$ & $\begin{array}{l}\text { No mutations } \\
\text { detected }\end{array}$ & $\begin{array}{l}\text { No mutations } \\
\text { detected }\end{array}$ & $\begin{array}{l}\text { No mutations } \\
\text { detected }\end{array}$ & $\begin{array}{l}\text { No mutations } \\
\text { detected }\end{array}$ & $\begin{array}{l}\mathrm{Nt} 720 \mathrm{G} \rightarrow \mathrm{T} \\
\mathrm{Nt} 761 \mathrm{C} \rightarrow \mathrm{T} \\
\mathrm{Nt} 807 \mathrm{C} \rightarrow \mathrm{T} \\
\mathrm{Nt} 830 \mathrm{C} \rightarrow \mathrm{A} \\
\mathrm{Nt} 852 \mathrm{~T} \rightarrow \mathrm{C} \\
\mathrm{Nt} 898 \mathrm{G} \rightarrow \mathrm{C}\end{array}$ & $\begin{array}{l}31 \text { CGT-->CTT } \\
93 \text { GTG-->GGC } \\
94 \text { CGC-->GAT } \\
95 \text { TAC -->ACA } \\
96 \text { AAG-->TGA } \\
\text { Nt289 del A } \\
99 \text { CGC-->GAC }\end{array}$ & $\begin{array}{l}\text { No mutations } \\
\text { detected }\end{array}$ \\
\hline 198-lp & Uk & $\mathrm{R}$ & $\mathrm{R}$ & $\mathrm{R}$ & $\mathrm{R}$ & $\mathrm{R}$ & $\begin{array}{l}\text { No mutations } \\
\text { detected }\end{array}$ & $\begin{array}{l}\text { No mutations } \\
\text { detected }\end{array}$ & $\begin{array}{l}\text { No mutations } \\
\text { detected }\end{array}$ & $\begin{array}{l}\text { No mutations } \\
\text { detected }\end{array}$ & $\begin{array}{l}\text { Nt } 485 \text { G-->A } \\
\text { Nt } 491 \text { G-->C }\end{array}$ & $\begin{array}{l}80 \text { GTG--> TTG } \\
84 \text { GGC-->TCG }\end{array}$ & $\begin{array}{l}\text { Nt } 225 \text { T-->G } \\
\text { Nt } 421 \text { G-->A }\end{array}$ \\
\hline
\end{tabular}




\begin{tabular}{|c|c|c|c|c|c|c|c|c|c|c|c|c|c|}
\hline & & & & & & & & & & & $\begin{array}{l}\mathrm{Nt} 492 \mathrm{C}->>\mathrm{A} \\
\mathrm{Nt} 493 \mathrm{~A}-->\mathrm{C} \\
\mathrm{Nt} 495 \mathrm{C}-->\mathrm{G} \\
\mathrm{Nt} 496 \mathrm{G}-->\mathrm{T}\end{array}$ & $\begin{array}{l}\text { 86 CGG-->CTG } \\
87 \text { GTG-->GGT } \\
88 \text { AAG-->GAA } \\
89 \text { GAC-->GGA } \\
90 \text { CTG-->TCC }\end{array}$ & Nt 521 G-->A \\
\hline & & \multicolumn{5}{|c|}{ Drug resistance } & \multicolumn{6}{|c|}{ Analyzed genes } & \\
\hline Isolate & Comorbidity & I & $\mathrm{R}$ & $\mathrm{E}$ & $\mathrm{S}$ & $\mathrm{Z}$ & $k a t \mathrm{G}$ & $\operatorname{inh} \mathrm{A}$ & $r p o \mathrm{~B}$ & $e m b \mathrm{~B}$ & $r r s$ & $r p s \mathrm{~L}$ & $p n c \mathrm{~A}$ \\
\hline 199-bi & Uk & $\mathrm{R}$ & $\mathrm{R}$ & $\mathrm{S}$ & S & S & $\begin{array}{l}\text { No mutations } \\
\text { detected }\end{array}$ & $\mathrm{C}-15 \mathrm{~T}$ & $\begin{array}{l}\text { No mutations } \\
\text { detected }\end{array}$ & $\begin{array}{l}\text { No mutations } \\
\text { detected }\end{array}$ & $\begin{array}{l}\text { No mutations } \\
\text { detected }\end{array}$ & $\begin{array}{l}86 \text { CGG-->CTG } \\
87 \text { GTG-->GGT } \\
88 \text { AAG-->GAA } \\
89 \text { GAC-->GGA } \\
90 \text { CTG-->CCT } \\
91 \text { CCT-->GCC } \\
92 \text { GGT-->TGG } \\
94 \text { CGC-->ACG } \\
95 \text { TAC-->AAT } \\
96 \text { AAG-->CCT }\end{array}$ & 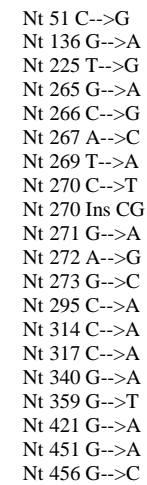 \\
\hline 228-ex & Uk & $\mathrm{R}$ & $\mathrm{R}$ & $\mathrm{S}$ & S & S & $\begin{array}{l}\text { No mutations } \\
\text { detected }\end{array}$ & $\mathrm{C}-15 \mathrm{~T}$ & $\begin{array}{l}\text { No mutations } \\
\text { detected }\end{array}$ & $\begin{array}{l}\text { No mutations } \\
\text { detected }\end{array}$ & $\begin{array}{l}\text { Nt } 483 \mathrm{G}-->\mathrm{A} \\
\mathrm{Nt} 491 \mathrm{G}-->\mathrm{T} \\
\mathrm{Nt} 493 \mathrm{~A}-->\mathrm{C} \\
\mathrm{Nt} 495 \mathrm{C}-->\mathrm{T} \\
\mathrm{Nt} 498 \mathrm{C}-->\mathrm{G} \\
\mathrm{Nt} 499 \mathrm{C}-->\mathrm{A} \\
\mathrm{Nt} 512 \mathrm{G}-->\mathrm{A}\end{array}$ & $\begin{array}{l}86 \text { CGG-->CGT } \\
90 \text { CTG-->GGA } \\
91 \text { CCT-->CAT } \\
92 \text { GGT-->GAC } \\
93 \text { GTG-->CTG } \\
94 \text { CGC-->GTG } \\
95 \text { TAC-->ACA } \\
96 \text { AAG-->GTC } \\
97 \text { ATC-->CCT } \\
98 \text { ATC-->CCC }\end{array}$ & $\begin{array}{l}\text { No mutations } \\
\text { detected }\end{array}$ \\
\hline
\end{tabular}

Table 3: Mutations characterized in rpoB RRDR

\begin{tabular}{lll}
\hline Isolate & Mutations along RRDR & Phenotypic rifampin resistance \\
\hline 33ex & 521 CTG-GTG (Leu-Val) & $\mathrm{S}$ \\
& 524 TTG-TTT (Leu-Phe) & \\
& 525 ACC-GAC (Thr-Asp) & \\
& 528 CGC-AGT (Arg-Ser) & \\
529 CGA-CAC (Arg-His) & $\mathrm{R}$ \\
530 CTG-TGG (Leu-Trp) & \\
\hline 52ex & 52 GCG-TGG (Ala-Trp) & CGA-CGC (Arg-Arg) \\
\end{tabular}

Table 4: Most frequent mutations characterized in $r r s$ and $r p s L$ genes

\begin{tabular}{|c|c|c|c|c|c|}
\hline \multirow[b]{2}{*}{ Gene } & \multicolumn{2}{|l|}{ Polymorphism } & \multirow[b]{2}{*}{ Aminoacid change } & \multirow{2}{*}{$\begin{array}{l}\text { Isolates with } \\
\text { polymorphism }\end{array}$} & \multirow{2}{*}{$\begin{array}{l}\text { Number of STR } \\
\text { resistant isolate }\end{array}$} \\
\hline & codon & nucleotide & & & \\
\hline \multirow[t]{7}{*}{$r r s$} & $162 \mathrm{GAA} \rightarrow \mathrm{GGA}$ & $485 \mathrm{~A} \rightarrow \mathrm{G}$ & Glu/Gly & 18 & 15 \\
\hline & $265 \mathrm{GTC} \rightarrow \mathrm{GTT}$ & $795 \mathrm{C} \rightarrow \mathrm{T}$ & $\mathrm{Val} / \mathrm{Val}$ & 11 & 8 \\
\hline & $290 \mathrm{TAC} \rightarrow \mathrm{TAA}$ & $870 \mathrm{C} \rightarrow \mathrm{A}$ & Tyr/Stop & 5 & 3 \\
\hline & $302 \mathrm{TCA} \rightarrow \mathrm{TCC}$ & $906 \mathrm{~A} \rightarrow \mathrm{C}$ & Ser/Ser & 2 & 2 \\
\hline & $302 \mathrm{TCA} \rightarrow \mathrm{TCT}$ & $906 \mathrm{~A} \rightarrow \mathrm{T}$ & Ser/Ser & 10 & 7 \\
\hline & $303 \mathrm{AAG} \rightarrow \mathrm{GAC}$ & $907 \mathrm{~A} \rightarrow \mathrm{G}$ & Lys/Asp & 7 & 6 \\
\hline & $303 \mathrm{AAG} \rightarrow \mathrm{TAG}$ & $907 \mathrm{~A} \rightarrow \mathrm{T}^{\mathrm{a}}$ & Lys/Stop & 2 & 2 \\
\hline \multirow[t]{9}{*}{$r p s \mathrm{~L}$} & $30 \mathrm{CGT} \rightarrow \mathrm{AGT}$ & $88 \mathrm{C} \rightarrow \mathrm{A}$ & $\mathrm{Arg} / \mathrm{Ser}$ & 6 & 6 \\
\hline & $31 \mathrm{CGT} \rightarrow \mathrm{CTT}$ & $92 \mathrm{G} \rightarrow \mathrm{T}$ & $\mathrm{Arg} / \mathrm{Leu}$ & 2 & 2 \\
\hline & $31 \mathrm{CGT} \rightarrow \mathrm{ATT}$ & $92 \mathrm{C} \rightarrow \mathrm{T}$ & & & \\
\hline & & $93 \mathrm{G} \rightarrow \mathrm{T}$ & Arg/Ile & 4 & 4 \\
\hline & $43 \mathrm{AAG} \rightarrow \mathrm{ACG}$ & $128 \mathrm{~A} \rightarrow \mathrm{C}$ & Lys/Thr & 1 & 1 \\
\hline & $43 \mathrm{AAG} \rightarrow \mathrm{AGG}$ & $128 \mathrm{~A} \rightarrow \mathrm{G}$ & Lys/Arg & 2 & 2 \\
\hline & $47 \mathrm{TCG} \rightarrow \mathrm{TGG}$ & $140 \mathrm{C} \rightarrow \mathrm{G}$ & Ser/Trp & 8 & 7 \\
\hline & $87 \mathrm{GTG} \rightarrow \mathrm{TGA}$ & $259 \mathrm{G} \rightarrow \mathrm{T}$ & & & \\
\hline & & $260 \mathrm{~T} \rightarrow \mathrm{G}$ & & & \\
\hline
\end{tabular}




\begin{tabular}{|c|c|c|c|c|}
\hline & $261 \mathrm{G} \rightarrow \mathrm{A}$ & Val/Stop & 4 & 4 \\
\hline $87 \mathrm{GTG} \rightarrow \mathrm{TTG}$ & $259 \mathrm{G} \rightarrow \mathrm{T}$ & Val/Leu & 1 & 0 \\
\hline \multirow[t]{3}{*}{$87 \mathrm{GTG} \rightarrow \mathrm{TGC}$} & $259 \mathrm{G} \rightarrow \mathrm{T}$ & & & \\
\hline & $260 \mathrm{~T} \rightarrow \mathrm{G}$ & & & \\
\hline & $261 \mathrm{G} \rightarrow \mathrm{C}$ & Val/Cys & 1 & 1 \\
\hline $87 \mathrm{GTG} \rightarrow \mathrm{CTG}$ & $259 \mathrm{G} \rightarrow \mathrm{C}$ & Val/Leu & 1 & 1 \\
\hline \multirow[t]{2}{*}{$87 \mathrm{GTG} \rightarrow \mathrm{GGT}$} & $260 \mathrm{~T} \rightarrow \mathrm{G}$ & & & \\
\hline & $261 \mathrm{G} \rightarrow \mathrm{T}$ & Val/Gly & 2 & 1 \\
\hline $87 \mathrm{GTG} \rightarrow \mathrm{GTA}$ & $261 \mathrm{G} \rightarrow \mathrm{A}$ & $\mathrm{Val} / \mathrm{Val}$ & 1 & 1 \\
\hline \multirow[t]{2}{*}{$88 \mathrm{AAG} \rightarrow \mathrm{GTG}^{\mathrm{a}}$} & $262 \mathrm{~A} \rightarrow \mathrm{G}$ & & & \\
\hline & $263 \mathrm{~A} \rightarrow \mathrm{T}$ & Lys/Val & 1 & 1 \\
\hline $88 \mathrm{AAG} \rightarrow \mathrm{AGG}$ & $263 \mathrm{~A} \rightarrow \mathrm{G}$ & Lys/Arg & 5 & 5 \\
\hline \multirow[t]{2}{*}{$88 \mathrm{AAG} \rightarrow \mathrm{AGA}^{\mathrm{a}}$} & $263 \mathrm{~A} \rightarrow \mathrm{G}$ & & & \\
\hline & $264 \mathrm{G} \rightarrow \mathrm{A}$ & Lys/Arg & 1 & 1 \\
\hline \multirow[t]{2}{*}{$88 \mathrm{AAG} \rightarrow \mathrm{GAA}^{\mathrm{a}}$} & $262 \mathrm{~A} \rightarrow \mathrm{G}$ & & & \\
\hline & $264 \mathrm{G} \rightarrow \mathrm{A}$ & Lys/Glu & 2 & 1 \\
\hline
\end{tabular}

\section{Discussion}

DR is a major cause of increasing TB incidence mainly due to mutations in target genes. Mutations in MTBc isolates have only been reported for high TB incidence states in Mexico. This report is the first insight into polymorphisms in target genes to INH, RIF, EMB, STR and PZA in southwest Mexico.

Mutations in $k a t \mathrm{G}$ and $\operatorname{inh} \mathrm{A}$ are the main cause of resistance to INH. It was reported that simultaneous mutations in both genes were responsible for DR to INH in other regions of the world (Mathuria et al., 2009; Gonçalves et al., 2012); nevertheless, our data coincide with previous evidence from Mexico about INH resistant $\mathrm{MTBc}$ isolates that hold mutations in either kat $\mathrm{G}$ or inhA genes (Ramaswamy et al., 2004; Molina-Torres et al., 2010; Zenteno-Cuevas et al., 2015). In this study no mutations in the analyzed regions were found in 18 phenotypically INH resistant isolates, suggesting that

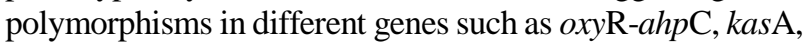
furA, fabG1, efp A, fad $\mathrm{E} 24$, ini $\mathrm{A}$, ini $\mathrm{B}$, ini $\mathrm{C}$, kas $\mathrm{A}, n a t, n d h$, Rv1772, Rv1592c, Rv0340, or srmR may be responsible for this behavior (Herrera-León et al., 2005; Seifert et al., 2015).

Twenty-one isolates were RIF resistant according to nitrate reductase assay, but just in six of them mutations in codons 516, 526 or 531 at $r p o \mathrm{~B}$ gene were found. RIF resistance of the remaining isolates may be explained by mutations in codons different to 516,526 or 531 or in other regions of rpoB out of RRDR (Zaw et al., 2018), this highlights the importance of sequencing the whole RRDR in order to associate new mutations to RIF resistance.

Polymorphisms in codon 531 are responsible for RIF resistance in over $60 \%$ of the cases around the world (Agapito et al., 2002; Bolotin et al., 2009; Gonçalves et al., 2012). In Mexico, mutation TCG531TTG has been previously reported in RIF resistant isolates (Cuevas-Cordoba et al., 2010; Zenteno-Cuevas et al., 2015; Lopez-Avalos et al., 2017); here, we report this same mutation which explains only $14.2 \%$ of RIF resistant isolates. It is worth mentioning that none of new mutations within RRDR found in this study in RIF resistant isolates were characterized in those with TCG531TTG mutation. This supports that TCG531TTG polymorphism itself is enough to cause RIF resistance.

Mutations in codon emb B306 are responsible for EMB resistance according to reports from Mexico, Cuba, Poland, China and Iran, among other countries (Guerrero et al., 2013; Cuevas-Cordoba et al., 2013; Li et al., 2016; Ramazanzadeh and Mohammadi, 2016), despite being also reported in susceptible isolates. Our findings confirm both facts, as one of the six isolates with mutation in emb B306 was susceptible while the five others were resistant to EMB. Other eighteen isolates were phenotypically resistant to EMB and at least to another drug, however no mutation in emb B306 was identified, probably they hold mutations in codons emb B406 or emb B497, described in resistant isolates (Bakuła et al., 2013), which were not included in the $324 \mathrm{pb}$ fragment analyzed here.

Studies conducted in Poland, Cameroon and Mexico reported mutually exclusive mutations in $r r s$ and $r p s \mathrm{~L}$ in STR resistant isolates (Cuevas-Córdoba et al., 2013a; Jagielski et al., 2014). In the present report, 28 phenotypically STR resistant isolates were identified, $4 / 28$ with mutations in rpsL, $13 / 28$ in rrs and 11/28 in both genes. Among those with $r r s$ mutations, polymorphisms at nucleotides $485 \mathrm{~A} \rightarrow \mathrm{G}, 906 \mathrm{~A} \rightarrow \mathrm{T} / \mathrm{C}$ and $907 \mathrm{~A} \rightarrow \mathrm{T} / \mathrm{G}$ were the most frequent. In fact, in two isolates, phenotypically resistant to STR, $A \rightarrow G$ mutation in nucleotide 485 was the only one characterized, suggesting its importance in STR resistance. Additionally, mutations at $r r s$ and $r p s \mathrm{~L}$ genes are reported here for the first time: $\mathrm{A} \rightarrow \mathrm{T}$ in nucleotide 907 in $r r s$ and codon $88 \quad$ AAG $\rightarrow$ GTG/GAA/AGA (Lys $\rightarrow$ Val/Glu/Arg) in rpsL. Mutation TCG $\rightarrow$ TGG (Ser $\rightarrow$ Trp) at codon 47 in rpsL was found in STR resistant isolates under three different circumstances: (a) simultaneously with mutations at nucleotides 485 , 906 and/or 907 in $r r s$ gene; (b) with a mutation at codon 88 in rps L gene and (c) alone, being responsible itself for STR resistance. Also, polymorphisms found at $r p s \mathrm{~L}$ gene in codon 87 seem to be important for resistance to the drug as they appeared in 8 resistant isolates. The high incidence of these polymorphisms suggests an important 
role in STR resistance which deserves further study. To our knowledge, this is the first report about mutations at codons 37 and 87 in rpsL related to STR resistance and the occurrence of simultaneous mutations in $r r s$ and $r p s \mathrm{~L}$ genes in STR resistant isolates.

Numerous mutations in pncA have been reported worldwide (Ramirez-Busby and Valafar, 2015) in both, PZA resistant and susceptible MTBc isolates. In this study, two out of seven isolates with mutations in pncA were phenotypically resistant to PZA, with 3 and 19 mutations respectively, none of them within any hot spot. This contrasts with a previous mexican report, in which several polymorphisms were characterized in PZA resistant isolates, including doble mutations (Cuevas-Córdoba et al., 2013). Our findings support the proposal of PZA resistance being due to altern cellular or molecular mechanisms such as mutations in rpsA gene (Barco et al., 2006; Akhmetova et al., 2015; Khan et al., 2018).

International studies report that DM is a major risk factor for tuberculosis infection and triples the risk of developing active TB (Jeon and Murray, 2008; Lutfiana et al., 2019). Studies conducted along Mexico indicate that between 19$40 \%$ of TB cases are associated to DM (Ponce de Leon et al., 2004; Jiménez-Corona et al., 2013; Delgado-Sanchez et al., 2015; Restrepo, 2016); in the present report, 31.5\% cases showed TB-DM association. Moreover, $50 \%$ of total TB-DM cases were MDR close to the $42.2 \%$ reported by in San Luis Potosí, a state located in Central Mexico (Gómez-Gómez et al., 2015). High incidence of TB among diabetic patients has been explained by metabolic and immunological alterations due to DM, although this has not been fully understood. Our data, confirm that more TB-DM patients are infected with MDR isolates than those without any comorbidity (50\% Vs. 25\%) which complicates their treatment. This highlights the importance of providing an acute TB diagnosis which includes resistance profile to first line antituberculous drugs, in order to provide an efficient and effective treatment to diabetic patients.

Most studies conducted in Mexico describe drug resistance based in phenotypic assays, only a few have described a correlation between drug resistance and mutations in target genes e.g., resistance to PZA and mutations in pncA (Cuevas-Córdoba et al., 2013) or resistance to STR and mutations in rrs/rps $\mathrm{L}$ (Cuevas-Córdoba et al., 2013). Our study reports the presence of mutations in seven different genes associated to resistance to five first line antimycobacterial drugs and the phenotypic drug resistance pattern observed in clinical isolates. Furthermore, to our knowledge, this is the first study to report simultaneous mutations in $r r s$ and $r s p \mathrm{~L}$ genes in STR resistant isolates and to stablish a correlation between comorbidites and mutations in target genes of first line antituberculous drugs in southwest Mexico.
In order to get a wider perspective of DR in this mexican region, it would be of great interest to study a larger number of clinical samples. Its molecular analysis should include search of mutations in regions related to DR besides those considered in this report such as codons 406 or 497 in $e m b \mathrm{~B}$ or the sequence out of RRDR in rpoB.

Our findings highlight that even punctual mutations have been useful in molecular diagnostic techniques to determine $\mathrm{DR}$, it is time to analyze longer fragments of target genes as new DR mutations are being reported continuously.

\section{Conclusion}

This is the first report about phenotypic drug resistance and molecular data in $\mathrm{MTBc}$ isolates from Oaxaca, Mexico, a region with scarce TB information. Most frequent mutations related to resistance to first line antituberculous drugs were identified in phenotypically resistant MTBc isolates. As also new mutations were found in $r p o \mathrm{~B}, r r s$ and $r p s \mathrm{~L}$ genes it is important to study a larger number of MTBc isolates in order to stablish the occurrence of mutations associated to drug resistance in this region as our findings differ from previous reports in this country. Of special concern is the urgency of an accurate TB diagnosis in diabetic patients as they seem to be good targets for drug resistant mycobacteria strains.

\section{Acknowledgement}

Sanger sequencing was supported by Universidad Autónoma Benito Juárez de Oaxaca through the Educational Institutions Quality Strengthening Program (PROFOCIE). Martinez-Cruz Perla Monica is a postgraduate student under CONACYT National Fellowship (94467).

\section{Author's contributions}

Martínez-Cruz, Perla Mónica: Conducted molecular and phenotypic experiments, data analysis and manuscript writing.

Nakamura-López, Yuko: Contributed to data analysis and manuscript writing.

Quintero-Hernández, Verónica: Academic advisor on molecular data and manuscript writing reviewer.

Pérez-Campos Mayoral, Laura: Academic advisor on molecular data and manuscript writing reviewer.

Martínez-Martínez, Lucía Lourdes: Designed and supervised the study and contributed to data analysis.

\section{Ethics}

All individuals included in this study, signed a written informed consent and answered a questionnaire to obtain socio-demographic and clinical data. The Ethical Committee on Investigation of the Consejo Estatal para la Prevencion y Control del Sida, OaxacaMexico, approved the protocol. 


\section{References}

Abass, N. A., Suleiman, K. M., \& El Jalii, I. M. (2010). Differentiation of clinical Mycobacterium tuberculosis complex isolates by their GyrB polymorphism. Indian journal of medical microbiology, 28(1), 26-29. doi.org/10.4103/0255-0857.58724

Abbadi, S. H., Sameaa, G. A., Morlock, G., \& Cooksey, R. C. (2009). Molecular identification of mutations associated with anti-tuberculosis drug resistance among strains of Mycobacterium tuberculosis. International Journal of Infectious Diseases, 13(6), 673-678. doi.org/10.1016/j.ijid.2008.10.006

Abilleira, F., Brum, C., von Groll, A., \& da Silva, P. E. (2014). Evaluación de la prueba de la nitrato reductasa directa en microplaca para la detección rápida de tuberculosis multirresistente y extensamente resistente a fármacos. Biomédica, 35(2), 285-91. doi.org/10.7705/biomedica.v35i2.2570

Agapito, J., Neyra, V., Castro, J., Accinelli, R., Rodríguez, I., \& Espinoza, J. R. (2002). Caracterización de las mutaciones en el gen $r p o \mathrm{~B}$ asociadas a la rifampicina en pacientes con tuberculosis pulmonar. Revista Peruana de Medicina Experimental y Salud Pública, 19(3), 117123. http://www.scielo.org.pe/scielo.php?pid=S1726$46342002000300003 \&$ script $=$ sci_arttext

Akhmetova, A., Kozhamkulov, U., Bismilda, V., Chingissova, L., Abildaev, T., Dymova, M., ... \& Ramanculov, E. (2015). Mutations in the pncA and rps A genes among 77 Mycobacterium tuberculosis isolates in Kazakhstan. The International Journal of tuberculosis and Lung Disease, 19(2), 179-184. doi.org/10.5588/ijtld.14.0305

Bakuła, Z., Napiórkowska, A., Bielecki, J., Augustynowicz-Kopeć, E., Zwolska, Z., \& Jagielski, T. (2013). Mutations in the $e m b B$ gene and their association with ethambutol resistance in multidrugresistant Mycobacterium tuberculosis clinical isolates from Poland. BioMed research international, 2013. doi.org/10.1155/2013/167954

Barco, P., Cardoso, R. F., Hirata, R. D. C., Leite, C. Q. F., Pandolfi, J. R., Sato, D. N., ... \& Hirata, M. H. (2006). pnc A mutations in pyrazinamide-resistant Mycobacterium tuberculosis clinical isolates from the southeast region of Brazil. Journal of antimicrobial chemotherapy, 58(5), 930-935. doi.org/10.1093/jac/dk1363

Bolotin, S., Alexander, D. C., Chedore, P., Drews, S. J., \& Jamieson, F. (2009). Molecular characterization of drug-resistant Mycobacterium tuberculosis isolates from Ontario, Canada. Journal of antimicrobial chemotherapy, 64(2), 263-266. doi.org/10.1093/jac/dkp183
Chimara, E., Ferrazoli, L., \& Leão, S. C. (2004). Mycobacterium tuberculosis complex differentiation using gyrB-restriction fragment length polymorphism analysis. Memórias do Instituto Oswaldo Cruz, 99, 745-748. doi.org/10.1590/S0074-02762004000700014

Cuevas-Cordoba, B., \& Zenteno-Cuevas, R. (2010). Drug resistant tuberculosis: molecular mechanisms and diagnostic methods. Enfermedades infecciosas y microbiologia clinica, 28(9), 621-628. doi.org/10.1016/j.eimc.2009.12.005

Cuevas-Córdoba, B., Cuellar-Sánchez, A., PasissiCrivelli, A., Santana-Álvarez, C. A., HernándezIllezcas, J., \& Zenteno-Cuevas, R. (2013a). rrs and $r p s \mathrm{~L}$ mutations in streptomycin-resistant isolates of Mycobacterium tuberculosis from Mexico. Journal of Microbiology, Immunology and Infection, 46(1), 30-34. doi.org/10.1016/j.cub.2017.05.064

Cuevas-Córdoba, B., Xochihua-González, S. O., Cuellar, A., Fuentes-Domínguez, J., \& Zenteno-Cuevas, R. (2013b). Characterization of $p n c \mathrm{~A}$ gene mutations in pyrazinamide-resistant Mycobacterium tuberculosis isolates from Mexico. Infection, Genetics and Evolution, 19, 330-334. doi.org/10.1016/j.meegid.2012.12.013

Cuevas-Córdoba, B., Juárez-Eusebio, D. M., AlmarazVelasco, R., Muñiz-Salazar, R., Laniado-Laborin, R., \& Zenteno-Cuevas, R. (2015). Mutation at $e m b \mathrm{~B}$ codon 306 , a potential marker for the identification of multidrug resistance associated with ethambutol in Mycobacterium tuberculosis. Antimicrobial agents and chemotherapy, 59(9), 5455-5462. doi.org/10.1128/AAC.00117-15

De Almeida, I. N., da Silva Carvalho, W., Rossetti, M. L., Dalla Costa, E. R., \& De Miranda, S. S. (2013). Evaluation of six different DNA extraction methods for detection of Mycobacterium tuberculosis by means of PCR-IS6110: preliminary study. BMC research notes, 6(1), 1-6. doi.org/10.1186/1756-0500-6-561

Delgado-Sánchez, G., García-García, L., CastellanosJoya, M., Cruz-Hervert, P., Ferreyra-Reyes, L., Ferreira-Guerrero, E., ... and Jiménez-Corona, M. E. (2015). Association of pulmonary tuberculosis and diabetes in Mexico: analysis of the national tuberculosis registry 2000-2012. PloS one, 10(6), e0129312. doi.org/10.1371/journal.pone.0129312

Fan, X. Y., Hu, Z. Y., Xu, F. H., Yan, Z. Q., Guo, S. Q., $\&$ Li, Z. M. (2003). Rapid detection of rpoB gene mutations in rifampin-resistant Mycobacterium tuberculosis isolates in Shanghai by using the amplification refractory mutation system. Journal of Clinical Microbiology, 41(3), 993-997. doi.org/10.1128/JCM.41.3.993-997.2003 
Gómez-Gómez, A., Magaña-Aquino, M., López-Meza, S., Aranda-Álvarez, M., Díaz-Ornelas, D. E., Hernández-Segura, M. G., ... \& Noyola, D. E. (2015). Diabetes and other risk factors for multi-drug resistant tuberculosis in a Mexican population with pulmonary tuberculosis: case control study. Archives of medical research, 46(2), 142-148. doi.org/10.1016/j.arcmed.2015.01.006

Gonçalves, M. G., Fukasawa, L. O., Oliveira, R. S., Salgado, M. M., Harrison, L. H., Shutt, K. A., \& Sacchi, C. T. (2012). Fast test for assessing the susceptibility of Mycobacterium tuberculosis to isoniazid and rifampin by real-time PCR. Memórias do Instituto Oswaldo Cruz, 107, 903-908. doi.org/10.1590/S0074-02762012000700011

Guerrero, E., Lemus, D., Yzquierdo, S., Vílchez, G., Muñoz, M., Montoro, E., \& Takiff, H. (2013). Association between embB mutations and ethambutol resistance in Mycobacterium tuberculosis isolates from Cuba and the Dominican Republic: reproducible patterns and problems. Revista Argentina de microbiologia, 45(1), 21-26. https://www.redalyc.org/pdf/2130/213026064004.pdf

Herrera-León, L., Molina, T., Saíz, P., Sáez-Nieto, J. A., \& Jiménez, M. S. (2005). New multiplex PCR for rapid detection of isoniazid-resistant Mycobacterium tuberculosis clinical isolates. Antimicrobial agents and chemotherapy, 49(1), 144-147.

doi.org/10.1128/AAC.49.1.144-147.2005

Huard, R. C., de Oliveira Lazzarini, L. C., Butler, W. R., van Soolingen, D., \& Ho, J. L. (2003). PCR-based method to differentiate the subspecies of the Mycobacterium tuberculosis complex on the basis of genomic deletions. Journal of clinical microbiology, 41(4), 1637-1650. doi.org/10.1128/JCM.41.4.1637-1650.2003

Jagielski, T., Ignatowska, H., Bakula, Z., et al. (2014). Screening for streptomycin resistance-conferring mutations in Mycobacterium tuberculosis clinical isolates from Poland. PLoS One, 9(6): e100078. doi.org/10.1371/journal.pone.0100078

Jeon, C. Y., \& Murray, M. B. (2008). Diabetes mellitus increases the risk of active tuberculosis: a systematic review of 13 observational studies. PLoS Med, 5(7), e152. doi.org/10.1371/journal.pmed.0050152

Jiménez-Corona, M. E., Cruz-Hervert, L. P., GarcíaGarcía, L., Ferreyra-Reyes, L., Delgado-Sánchez, G., Bobadilla-del-Valle, M., ... \& Ponce-de-León, A. (2013). Association of diabetes and tuberculosis: impact on treatment and post-treatment outcomes. Thorax, 68(3), 214-220. doi.org/10.1136/thoraxjnl-2012-201756

Khan, M. T., Rehaman, A. U., Junaid, M., Malik, S. I., \& Wei, D. Q. (2018). Insight into novel clinical mutants of RpsA-S324F, E325K and G341R of Mycobacterium tuberculosis associated with pyrazinamide resistance. Computational and structural biotechnology journal, 16, 379-387. doi.org/10.1016/j.csbj.2018.10.012
Li, Y., Wang, Y., Zhang, Z., Gao, H., Wang, H., Cao, J., ... \& Dai, E. (2016). Association between embB codon 306 mutations, phenotypic resistance profiles and genotypic characterization in clinical Mycobacterium tuberculosis isolates from Hebei, China. Antimicrobial agents and chemotherapy, 60(12), 7295-7302. doi.org/10.1128/AAC.00532-16

Lopez-Avalos, G., Gonzalez-Palomar, G., LopezRodriguez, M., Vazquez-Chacon, C. A., MoraAguilera, G., Gonzalez-Barrios, J. A., ... \& AlvarezMaya, I. (2017). Genetic diversity of Mycobacterium tuberculosis and transmission associated with firstline drug resistance: a first analysis in Jalisco, Mexico. Journal of global antimicrobial resistance, 11, 90-97. doi.org/10.1016/j.jgar.2017.07.004

Lutfiana, N. C., van Boven, J. F., Masoom Zubair, M. A., Pena, M. J., \& Alffenaar, J. W. C. (2019). Diabetes mellitus comorbidity in patients enrolled in tuberculosis drug efficacy trials around the world: a systematic review. British journal of clinical pharmacology, 85(7), 1407-1417. doi.org/10.1111/bcp. 13935

Madeira, F., Park, Y.M., Lee, J., et al. (2019). The EMBLEBI search and sequence analysis tools APIs in 2019. Nucleic Acids Res, 47(W1): W636-W641. doi.org/10.1093/nar/gkz268

Malone, K. M., \& Gordon, S. V. (2016). Antibiotic methylation: a new mechanism of antimicrobial resistance. Trends in microbiology, 24(10), 771-772. doi.org/10.1016/j.tim.2016.08.003

Mathuria, J. P., Nath, G., Samaria, J. K., \& Anupurba, S. (2009). Molecular characterization of INH-resistant Mycobacterium tuberculosis isolates by PCR-RFLP and multiplex-PCR in North India. Infection, Genetics and Evolution, 9(6), 1352-1355. doi.org/10.1016/j.meegid.2009.09.008

Mokrousov, I., Narvskaya, O., Limeschenko, E., Otten, T., \& Vyshnevskiy, B. (2002). Detection of ethambutol-resistant Mycobacterium tuberculosis strains by multiplex allele-specific PCR assay targeting emb B306 mutations. Journal of Clinical Microbiology, 40(5), 1617-1620. doi.org/10.1128/JCM.40.5.1617-1620.2002

Molina-Torres, C. A., Moreno-Torres, E., OcampoCandiani, J., Rendon, A., Blackwood, K., Kremer, K., ... \& Vera-Cabrera, L. (2010). Mycobacterium tuberculosis spoligotypes in Monterrey, Mexico. Journal of clinical microbiology, 48(2), 448-455. doi.org/10.1128/JCM.01894-09

Nagarajan, S., Murugkar, H. V., Tosh, C., Behera, P., Khandia, R., Jain, R., ... \& Dubey, S. C. (2012). Comparison of a nucleoprotein gene based RT-PCR with real time RT-PCR for diagnosis of avian influenza in clinical specimens. Research in veterinary science, 93(1), 504-507. doi.org/10.1016/j.rvsc.2011.06.005 
OMS. (2012). Updated interim critical concentrations for first and second-line DST.

Pang, Y., Zhu, D., \& Zheng, H. (2017). Prevalence and molecular characterization of pyrazinamide resistance among multidrug-resistant Mycobacterium tuberculosis isolates from Southern China. BMC Infect Dis, 17(1), 711. doi.org/10.1186/s12879-017-2761-6

Peres, R. L., Maciel, E. L., Morais, C. G., Ribeiro, F. C. K., Vinhas, S. A., Pinheiro, C., ... \& Palaci, M. (2009). Comparison of two concentrations of NALC$\mathrm{NaOH}$ for decontamination of sputum for mycobacterial culture. The International journal of tuberculosis and lung disease, 13(12), 1572-1575. https://www.ingentaconnect.com/content/iuatld/ijtld/ 2009/00000013/00000012/art00024

Ponce-de-Leon, A., de Lourdes Garcia-Garcia, M., Garcia-Sancho, M. C., Gomez-Perez, F. J., Valdespino-Gomez, J. L., Olaiz-Fernandez, G., ... \& Sifuentes-Osornio, J. (2004). Tuberculosis and diabetes in southern Mexico. Diabetes care, 27(7), 1584-1590. doi.org/10.2337/diacare.27.7.1584

Ramaswamy, S. V., Dou, S. J., Rendon, A., Yang, Z., Cave, M. D., \& Graviss, E. A. (2004). Genotypic analysis of multidrug-resistant Mycobacterium tuberculosis isolates from Monterrey, Mexico. Journal of medical microbiology, 53(2), 107-113. doi.org/10.1099/jmm.0.05343-0

Ramazanzadeh, R., \& Mohammadi, B. (2016). Mutations in $e m b \mathrm{~B}$ gene associated with resistance to ethambutol in Mycobacterium tuberculosis strains isolated from TB patients in the west of Iran (2014-15). International journal of mycobacteriology, 5, S140., 59(9), 5267-5277. doi.org/10.1016/j.ijmyco.2016.11.013
Ramirez-Busby, S. M., \& Valafar, F. (2015). Systematic review of mutations in pyrazinamidase associated with pyrazinamide resistance in Mycobacterium tuberculosis clinical isolates. Antimicrobial agents and chemotherapy, 59(9), 5267-5277. doi.org/10.1007/978-3-319-97367-8_1

Restrepo, B.I. (2016). Diabetes and tuberculosis. Microbiol Spectr, 4(6). doi.org/10.1128/microbiolspec.TNMI7-0023-2016

Sandgren, A., Strong, M., Muthukrishnan, P., Weiner, B. K., Church, G. M., \& Murray, M. B. (2009). Tuberculosis drug resistance mutation database. PLoS medicine, 6(2), e1000002. doi.org/10.1371/journal.pmed.1000002

Seifert, M., Catanzaro, D., Catanzaro, A., \& Rodwell, T. C. (2015). Genetic mutations associated with isoniazid resistance in Mycobacterium tuberculosis: a systematic review. PloS one, 10(3), e0119628. doi.org/10.1371/journal.pone.0119628

WHO. (2019). Global status report on alcohol and health 2018. World Health Organization. ISBN-10: 9241565632.

Zaw, M. T., Emran, N. A., \& Lin, Z. (2018). Mutations inside rifampicin-resistance determining region of rpoB gene associated with rifampicin-resistance in Mycobacterium tuberculosis. Journal of infection and public health, 11(5), 605-610. doi.org/10.1016/j.jiph.2018.04.005

Zenteno-Cuevas, R., Xochihua-Gonzalez, O., CuevasCórdoba, B., Victoria-Cota, N. L., Muñiz-Salazar, R., Montero, H., ... \& Lauzardo, M. (2015). Mutations conferring resistance to first-and second-line drugs in multidrug-resistant Mycobacterium tuberculosis clinical isolates in southeast Mexico. International journal of antimicrobial agents, 45(6), 671-673. doi.org/10.1016/j.ijantimicag.2015.02.006 